\title{
FISCAL FEDERALISM AND ENDOGENOUS LOBBIES' FORMATION
}

\author{
MASSIMO BORDIGNON \\ LUCA COLOMBO \\ UMBERTO GALMARINI
}

CESIFO WORKING PAPER No. 1017

CAtegory 1: Public FinAnCE

August 2003

\footnotetext{
An electronic version of the paper may be downloaded

- from the SSRN website:

www.SSRN.com

- from the CESifo website: www.CESifo.de
} 


\title{
FISCAL FEDERALISM AND ENDOGENOUS LOBBIES' FORMATION
}

\begin{abstract}
We study lobbying behavior by firms in a two-region economy, with either centralized or decentralized provision of profit-enhancing local public goods. Firms compete either in the market, lobbying for public good provision once entered in a market, or for the market, lobbying to gain ccess to it. When firms compete in the market, we show that lobbying is unambiguously less disruptive or social welfare under decentralization. Moreover, foreign rather than domestic private nterests may be more powerful in a.ecting regional policies. On the contrary, when firms compete or the market, lobbying is mostly e.ective under decentralization, since local firms always end $\mathrm{p}$ forming a local monopoly. However, we show that an institutional setting in which competencies re split between the center and the periphery may dominate either full centralization or full ecentralization or both.
\end{abstract}

JEL Code: D70, H23, H77

Keywords: fiscal federalism, lobbying, private interests.

Massimo Bordignon

Istituto di Economia e Finanza

Università Cattolica

Largo Gemelli 1

20123 Milano

Italy
Luca Colombo

Istituto di Economia e Finanza

Università Cattolica

Largo Gemelli 1

20123 Milano

Italy

lucava.colombo@unicatt.it

\author{
Umberto Galmarini \\ Istituto di Scienze Giuridiche \\ Università degli Studi dell'Insubria \\ Viale Cavallotti 5 \\ 22100 Como \\ Italy
}

We thank conference participants at the 2003 North American Summer meeting of the Econometric Society, Kellogg School of Management, Northwestern University, June 2003, and at the conference on "Lobbying and Institutional Structure of Policy Making", University of Rome "La Sapienza", September 2002. We also thank Andrea Boitani, Paolo Liberati and Andrea Prat for their constructive remarks on previous versions of the paper. Usual disclaimers apply. 


\section{Introduction}

One of the most interesting recent institutional developments in world economies is a marked and widespread tendency toward decentralization within countries accompanied by an enlargement of international unions among countries. In the nineties about $95 \%$ of all countries in the world undertook steps toward a decentralization of functions to local governments. In some cases, this tendency was so strong to bring about the dissolution of previously existing political entities (Bolton et al., 1996, Alesina et al., 2000). At the same time, new international forms of cooperation where established (i.e. the Nafta treaty) and old ones were expanded (i.e. the European Union). These events generated a renewed interest by academic economists on the issue of the optimal organization of governments (e.g. Besley and Coate, 2002, Lockwood, 2002, Bordignon et al., 2001, Alesina et al., 2003). On average, this scrutiny tended to confirm Oates's (1972) intuition on the existence of potentially important efficiency gains associated with decentralization. However, some policy oriented economists remained highly skeptical. For example, in a very influential policy paper, Prud'homme (1995) severely warned against "the dangers of decentralization". His main (efficiency) argument against decentralization lies in a (presumed) stronger influence of corruption and lobbying by local interest groups on local governments. Recent empirical studies do not substantiate this hypothesis (e.g. Fisman and Gatti, 2002). Nonetheless, it is quite common to hear Prud'homme's type of arguments being repeated in political and economic circles as, for example, in the recent debate on whether competition policy should remain in the hands of the European Commission or being partly decentralized to member countries. The issue seems therefore to deserve a more detailed analysis.

Surprisingly enough, while there is a large economic literature on interest groups' influence on policy (e.g. Grossman and Helpman, 2001), very few studies have concentrated on the specific issue of the relationship between interest groups and decentralization. De Melo et al. (1993) find a positive correlation between decentralization and lobbying, due to the existence of a preference dilution effect. More recently, Redoano (2002) shows that the net effect of decentralization on lobbying is a priori uncertain. However, these studies only focus on the higher heterogeneity of preferences under centralization as the main engine for lobbies' formation and influence. Prud'homme's argument, on the other hand, has nothing to do with preferences heterogeneity. It relies instead on a greater "disposition" by local governments to "accept" pressures from local interests, presumably due to the fact that supporting a local interest may generate additional benefits for the local politician than supporting an external one.

To focus on this issue, we build a simple general equilibrium model in which we abstract entirely from heterogeneity of preferences. In our model, there are two regions, one resident firm and a large mass of consumers in each region owning the local firm. The two firms may serve both local markets and in all cases they have an incentive to lobby the governments in charge either to gain access to the local markets or to increase the production of a local public good which is complementary in consumption to the good they sell. We focus on two polar cases, one where all decisions are taken at the central level and the other where all decisions are taken at local level. For simplicity, and also because these effects are already well understood, we abstract entirely from "common pool" effects which may arise out of transfers from the central level to the local one (Persson, 1998), as well as from "fiscal competition" effects which may arise out of the mobility of the tax base (Wilson, 1999) or by "spillover effects" either in local public good production or taxation (Besley and Coate, 2002, Keen and Kotsogiannis, 2002). In our model, nobody moves, there are no spillover 
effects on either the demand or the supply side of regions, there are no intergovernmental transfers, and each local government finances its supply of local public good out of resident taxation, so as to rule out tax competition effects. The only source of difference we allow between centralization and decentralization is that the central government internalizes as components of social welfare the profits that both firms make in both markets, while under decentralization the local government is only interested to the profits that are made everywhere by its own resident firm (as they increase resident consumers' income). This captures in the simplest possible way the idea we discussed above that local interests may have a larger weight on local governments' welfare function.

In this setting, we ask what are the effects of lobbying on economic outcomes and social welfare in the two cases of decentralization and centralization. We consider two forms of lobbying. In the first one, firms lobby in the market; that is, firms have already gained access to both markets and have an incentive to lobby politicians to increase local public good production. In the second one, firms lobby for the market; that is, they lobby politicians to gain access to local markets.

We get very sharp results. When lobbying is in the market, lobbying behavior under centralization is always at least as bad for social welfare as under decentralization. Under decentralization, when both firms lobby both local politicians, local public goods supply is as distorted as under centralization (and so is social welfare), but lobbies pay higher contributions and so are worse off. However, under decentralization there are also equilibria where each firm lobbies only one politician at the time, while this is not possible under centralization. In this case, contributions are lower and so are the distortions in social welfare. Contrary to common intuition, we show that in many cases it is the foreign firm to lobby local politicians, rather than the home firm. The intuition here is simply that foreign contributions have a larger weight for politicians than contributions from local firms, as the latter contributions also reduce resident consumers' welfare.

Results are reversed when lobbying is for the market. Under decentralization lobbying always leads the local politicians to give access to the market to the resident firm only, although a duopoly may be better for social welfare. No matter the degree of politicians' benevolence, in fact, the local firm can always outbid the foreign firm to gain access to the market, because only this firm's profits matter for the local politicians' welfare. Under centralization, on the contrary, this effect is absent, which makes the central politician more resilient to lobbying. Finally, we also show that when lobbying is for the market the most effective institutional structure against lobbying distortions may be an intermediate one between centralization and decentralization. Under this structure, which we term "split competencies", decisions about the number of firms in each market are given to the central government, while decisions about local public good supply are allocated to local governments.

The rest of the paper is organized as follows. In section 2 we set up the model. In section 3 we examine the policy makers' choices in the benchmark situation of no lobbying. In section 4 we examine lobbying behavior when both firms compete and lobby in the market. In section 5 we study lobbying for the market. Section 6 concludes. All proofs and further technical details are in the appendix.

\section{The model}

The economy is composed of two identical regions indexed by $r \in\{a, b\}$. There are four goods: two private consumption goods, $x$ and $z$, a production factor, $y$, and a public 
investment good, $g$. The latter is purely local, meaning that there is a distinct provision in each region with no spillover effects across regions. In each region live a continuum of identical consumers with a mass of unity, not moving across regions, and there is a firm producing good $x$, indexed by $\rho \in\{\alpha, \beta\}$, where $\alpha$ and $\beta$ are the firms located in regions $a$ and $b$, respectively. In both regions consumers are endowed with a fixed quantity $\bar{y}>0$ of the production factor and have identical preferences represented by the quasi-linear utility function

$$
u\left(x_{r}, z_{r}, g_{r}\right)=x_{r}-\frac{x_{r}^{2}}{2 g_{r}}+z_{r} .
$$

We take good $z$ to be the numeraire and its (national) market to be perfectly competitive. Technology is linear and units are normalized so that the production of one unit of $z$ requires one unit of input $y$. These assumptions imply that in equilibrium profits in the production of good $z$ are zero and that its supply is perfectly elastic. Moreover, the market price of factor $y$ is equal to one.

Firms $\alpha$ and $\beta$ are entirely owned by consumers living in regions $a$ and $b$, respectively, and their profits are entirely distributed to shareholders. ${ }^{1}$ Hence, consumers' income is composed of two terms: the market value of the fixed endowment of good $y$, and the distributed firms' profits, net of contributions to the politicians, if any. Consumer's income in region $r$ is subject to a proportional income tax at rate $t_{r}, t_{r} \in[0,1)$. We let $p_{r}$ be the price of good $x$ in region $r, \Pi_{\rho r}$ be the profits (gross of contributions) earned by firm $\rho$ in region $r$, and $s_{\rho r}$ be the contributions to politicians by firm $\rho$ for public good $g_{r}$. To simplify the presentation, and without loss of generality (given symmetry between regions), in what follows we focus on region $a$. We denote with $\pi_{\alpha}=\Pi_{\alpha a}-s_{\alpha a}+\Pi_{\alpha b}-s_{\alpha b}$ the profits distributed by firm $\alpha$. Taking $g_{a}$ and $\pi_{\alpha}$ as given, each consumer in region $a$ solves:

$$
\begin{array}{ll}
\max _{x_{a}, z_{a}} & x_{a}-\frac{x_{a}^{2}}{2 g_{a}}+z_{a}, \\
\text { s.t. } & p_{a} x_{a}+z_{a} \leq\left(1-t_{a}\right)\left(\bar{y}+\pi_{\alpha}\right),
\end{array}
$$

from which we immediately obtain the inverse demand function for good $x_{a}$ as

$$
p_{a}\left(x_{a}, g_{a}\right)=1-\frac{x_{a}}{g_{a}} .
$$

From (2) it is apparent that for any given quantity $x_{a}>0$ an increase in $g_{a}$ increases the marginal willingness to pay for good $x_{a}$.

\subsection{The markets for $\operatorname{good} x$}

In each region good $x$ is traded in a local duopoly, with one of the firms located within the region and the other one outside it. Firms maximize profits and compete $\grave{a}$ la Cournot. Good $y$ is the only input into production and technology is linear, so that marginal costs are constant. There is however a source of asymmetry between firms. When a firm supplies to its own regional market (at "home"), the production function is $x=y / c$ (the marginal cost is $c>0$ ), while when a firm supplies "abroad" the production function is $x=y /(\delta c)$,

\footnotetext{
${ }^{1}$ Given quasi-linearity of the utility function, by which all income effects fall on the demand of good $z$, the equilibrium of the economy is independent of the distribution of profits across consumers and across regions.
} 
$\delta \geq 1$ (the marginal cost is $\delta c$ ), so that the home firm has a cost advantage over its competitor. $^{2}$

Denote with $x_{\rho r}$ the quantity sold by firm $\rho$ in region $r$; hence aggregate sales in regions $a$ and $b$ can be written as $x_{a}=x_{\alpha a}+x_{\beta a}$ and $x_{b}=x_{\alpha b}+x_{\beta b}$. Using (2), firm $\alpha$ solves:

$$
\begin{aligned}
\max _{x_{\alpha a}, x_{\alpha b}} \quad \Pi_{\alpha a}+\Pi_{\alpha b}= \\
\quad=\left(1-\frac{x_{\alpha a}+x_{\beta a}}{g_{a}}-c\right) x_{\alpha a}+\left(1-\frac{x_{\alpha b}+x_{\beta b}}{g_{b}}-\delta c\right) x_{\alpha b .}
\end{aligned}
$$

Solving this problem and the symmetric one for firm $\beta$, we obtain the equilibrium quantities

$$
\begin{aligned}
& x_{\alpha a}^{*}=h g_{a}, \quad x_{\beta b}^{*}=h g_{b}, \quad x_{\beta a}^{*}=f g_{a}, \quad x_{\alpha b}^{*}=f g_{b}, \\
& x_{a}^{*}=(h+f) g_{a}, \quad x_{b}^{*}=(h+f) g_{b},
\end{aligned}
$$

and the equilibrium prices

$$
p_{a}^{*}=p_{b}^{*}=p^{*}, \quad p^{*}=1-(h+f),
$$

where

$$
h=\frac{1+\delta c-2 c}{3}, \quad f=\frac{1+c-2 \delta c}{3} .
$$

To ensure that the quantities (and the respective prices) supplied by each firm in both regions are non-negative, we impose the following restrictions on parameters:

Assumption $10<c<1$ and $1 \leq \delta \leq \delta_{\max }=\frac{1+c}{2 c}$.

This framework allows for a wide range of market structures. When $\delta=1$, then $h=f=(1-c) / 3$, so that there is a symmetric duopoly in each region, since the "home" firm has no cost advantage over its "foreign" rival. At the other extreme, when $\delta=\delta_{\max }$, $h=(1-c) / 2$ and $f=0$. The cost advantage of the "home" firm is so high that the "foreign" firm does not enter the market, and thus there is a monopoly in each region. A continuum of intermediate cases is obtained for $\delta \in\left(1, \delta_{\max }\right)$.

Notice that the equilibrium gross profits are linearly increasing in public good provision, so that firms' managers have an incentive to lobby the policy maker(s) for an expansion in the provision of the public goods:

$$
\Pi_{\alpha}^{*}=\Pi_{\alpha a}^{*}+\Pi_{\alpha b}^{*}=h^{2} g_{a}+f^{2} g_{b}, \quad \Pi_{\beta}^{*}=\Pi_{\beta a}^{*}+\Pi_{\beta b}^{*}=f^{2} g_{a}+h^{2} g_{b} .
$$

\subsection{The public sector}

We consider two institutional settings. One is a centralized system, in which a single policy maker chooses the supply of public goods in both regions. The other is a decentralized one, in which each region is characterized by an independent policy maker choosing the

\footnotetext{
${ }^{2}$ For instance, the parameter $\delta$ (strictly speaking, $\delta-1$ ) can be interpreted as representing the extra transportation costs needed to transfer one unit of good $x$ across regions. We take the industrial structure as given. In particular, we do not allow for a firm located in one region to open a new plant in the other region so as to avoid paying the extra cost.
} 
local level of the public good. In both cases we assume public goods production to be financed with the residence-based income-tax. Technology for public good production shows decreasing returns, with factor $y$ used as the only input. The corresponding cost function is assumed to be of the form $\phi g_{r}^{2}, \phi>0$. In order to ease the notation, and without any loss of generality, we let $\phi=1 / 4$.

Under a centralized system, a single decision maker chooses $g_{a}$ and $g_{b}$ and sets a uniform tax rate across regions, $t_{a}=t_{b}=t$. The budget constraint is then:

$$
\frac{g_{a}^{2}+g_{b}^{2}}{4}=t\left(\pi_{\alpha}^{*}+\pi_{\beta}^{*}+2 \bar{y}\right)
$$

where $\pi_{\rho}^{*}=\Pi_{\rho}^{*}-s_{\rho a}-s_{\rho b}$.

Under a decentralized system, each regional policy maker independently and simultaneously chooses public good provision in her own region, and public expenditure is financed through the local income tax. The regional budget constraints are then:

$$
\frac{g_{a}^{2}}{4}=t_{a}\left(\pi_{\alpha}^{*}+\bar{y}\right), \quad \frac{g_{b}^{2}}{4}=t_{b}\left(\pi_{\beta}^{*}+\bar{y}\right) .
$$

Notice that by Walras' law the markets for good $z$ and factor $y$ also clear. ${ }^{3}$

\subsection{Social welfare}

To compare the two alternative arrangements, we need a normative criteria. Let us then define social welfare as the sum of consumers' surplus, distributed profits, and the contributions raised by the government. ${ }^{4}$ Substituting the equilibrium values for $x_{a}^{*}$, $z_{a}^{*}=-p^{*} x_{a}^{*}+\left(1-t_{a}\right)\left(\bar{y}+\pi_{\alpha}^{*}\right)$, and $\pi_{\alpha}^{*}$ into the utility function of consumers (1), social welfare in region $a$ is

$$
\mathcal{W}_{a}=x_{a}^{*}-\frac{\left(x_{a}^{*}\right)^{2}}{2 g_{a}}-p^{*} x_{a}^{*}+\left(1-t_{a}\right)\left(\bar{y}+\Pi_{\alpha a}^{*}-s_{\alpha a}+\Pi_{\alpha b}^{*}-s_{\alpha b}\right)+s_{\alpha a}+s_{\beta a}
$$

which using (4), (6), and (8), can be rewritten as

$$
\mathcal{W}_{a}\left(g_{a}, g_{b}\right)=W_{a}\left(g_{a}, g_{b}\right)-s_{\alpha b}+s_{\beta a}
$$

where

$$
W_{a}\left(g_{a}, g_{b}\right)=\frac{(h+f)^{2} g_{a}+2\left(h^{2} g_{a}+f^{2} g_{b}\right)}{2}-\frac{g_{a}^{2}}{4}+\bar{y} .
$$

\footnotetext{
${ }^{3}$ The supply of good $z$ is perfectly elastic and thus its equilibrium quantity is determined by national demand, $z^{d}$, from consumers. As for factor $y$, national supply from consumers is inelastic, $y^{s}=2 \bar{y}$. The demand for $y$ comes from three sources: the public sector $\left(y_{P S}^{d}\right)$, the firms producing good $z\left(y_{Z}^{d}\right)$, and the firms $\alpha$ and $\beta\left(y_{\alpha+\beta}^{d}\right)$. By Walras' law, given that the centralized public sector's budget constraint balances, it follows that $y_{Z}^{d}+y_{P S}^{d}+y_{\alpha+\beta}^{d}=y^{s}$, where $y_{P S}^{d}=\left(g_{a}^{2}+g_{b}^{2}\right) / 4, y_{Z}^{d}=z^{d}=2 \bar{y}+\pi_{\alpha}^{*}+\pi_{\beta}^{*}-p^{*}\left(x_{a}^{*}+x_{b}^{*}\right)$, $y_{\alpha+\beta}^{d}=c\left(x_{\alpha a}^{*}+\delta x_{\alpha b}^{*}+x_{\beta b}^{*}+\delta x_{\beta a}^{*}\right)$. The same holds under decentralization.

${ }^{4}$ Alternatively, we could have defined social welfare as the sum of consumer's surplus and distributed profits, letting contributions enter the choice function of the government (see eq. 17 below) only as a separate component. Our main results would remain valid under this alternative definition of social welfare.
} 
National social welfare, $\mathcal{W}=\mathcal{W}_{a}+\mathcal{W}_{b}$, is then

$$
\mathcal{W}\left(g_{a}, g_{b}\right)=\frac{(h+f)^{2}+2\left(h^{2}+f^{2}\right)}{2}\left(g_{a}+g_{b}\right)-\frac{g_{a}^{2}+g_{b}^{2}}{4}+2 \bar{y}
$$

Comparing these equations, we notice an important difference. The net effect of lobbyists' contributions on national social welfare is nil, since they are a pure transfer from lobbyists to politicians. Hence, a fully benevolent social planner under centralization should not take them into account. However, this is not true under decentralization. In this case, a contribution of firm $\alpha$ to the policy maker of region $b$ counts as a welfare loss in region $a$, whereas a contribution of firm $\beta$ to the policy maker of region $a$ counts as a welfare gain in region $a$. Hence, under decentralization, increasing the contributions from foreign firms to home politicians and reducing own firms contributions to foreign politicians count as a net increase in social welfare and as such should be considered by a benevolent planner.

\section{$3 \quad$ Optimal public good provision without lobbying}

Let us begin our analysis by examining policy choices in the benchmark case of no lobbying. Under centralization, the benevolent social planner would choose public goods supply by maximizing (11), giving for both $g_{a}$ and $g_{b}$ :

$$
\hat{g}^{C}=(h+f)^{2}+2\left(h^{2}+f^{2}\right) .
$$

Under decentralization, on the other hand, the policy maker of region $a$ would maximize (10) with respect to $g_{a}$, taking $g_{b}$ as given (and an analogous problem is solved by the policy maker in region $b$ ), obtaining the symmetric solution

$$
\hat{g}^{D}=(h+f)^{2}+2 h^{2} .
$$

By using (6), (12) and (13), equilibrium profits of each firm under centralization and decentralization are:

$$
\begin{aligned}
& \hat{\pi}^{C}=\left(h^{2}+f^{2}\right) \hat{g}^{C}, \\
& \hat{\pi}^{D}=\left(h^{2}+f^{2}\right) \hat{g}^{D} .
\end{aligned}
$$

It follows:

Proposition 1 Suppose there is no lobbying. Then if $\delta \in\left[1, \delta_{\max }\right)$ public good supply, national social welfare and firms' profits are higher under centralization than under decentralization. In the limiting case $\delta=\delta_{\max }$, the two regimes are equivalent.

Proof. The part on public good supply and firms' profits follows from $f^{2}>0$ if $\delta \in\left[1, \delta_{\max }\right)$ and $f^{2}=0$ if $\delta=\delta_{\max }$, and by comparison of (12)-(13) and of (14)-(15), respectively. As for aggregate social welfare, since $g_{a}=g_{b}=\hat{g}^{C}$ is a global maximum of (11), the latter is not maximized for $g_{a}=g_{b}=\hat{g}^{D}<\hat{g}^{C}$.

The intuition is simple. When a regional policy maker considers an increase in local public good supply, she does not internalize as social welfare gains the additional profits made by the non-resident firm. Hence, when both firms sell in both regions, local public good supply is lower under decentralization and so are profits and national welfare. On the contrary, a centralized policy maker internalizes the entire firms' profit gains, and hence she has a greater incentive to expand public good supply. These incentives are the same when the resident firm is a monopoly within its own region, and hence $\hat{g}^{C}=\hat{g}^{D}$. 


\section{Lobbying in the market}

We now consider the effect of introducing lobbying into the model. We consider two different cases, lobbying in the market and lobbying for the market. In the first case, firms are already present in the market and have an incentive to lobby politicians to increase public good supply, as this increases their profits. In the second case, firms compete to acquire the right to produce in the market. In both cases, we derive equilibrium contributions and social welfare in the two cases of centralization and decentralization and compare the results.

In this section, we analyze the case of lobbying in the market. In this framework, we study lobbying behavior using the common agency approach developed by Bernheim and Whinston (1986) and popularized by Dixit et al. (1997). Notice however that under decentralization, as there are two principals (firms $\alpha$ and $\beta$ ) lobbying two agents (policy makers $a$ and $b$ ), our model combines elements of both the common agency model and the one-principal many-agents model (on the latter, see for instance Mookherjee, 1984, and Ma, 1988). We examine first the case of a centralized system.

\subsection{Centralization}

A lobby maximizes profits net of contributions to the policy maker, who in turn maximizes a weighted average of social welfare and lobbyists' contributions. As for the timing, we assume that firms move first, by independently and simultaneously offering the policy maker a contribution schedule defining its monetary contribution as a function of public good provision. Second, upon acceptance of the lobbies contributions, the policy maker chooses public goods supply.

Following Dixit et al. (1997), we focus on truthful equilibria, in which each lobby offers the policy maker a non-negative compensating contribution schedule, shaped along its iso-profit curve. Firm $\rho$ 's compensating contribution schedule is defined as

$$
S_{\rho}\left(g_{a}, g_{b}, \pi_{\rho}\right)=\max \left\{h^{2} g_{r}+f^{2} g_{-r}-\pi_{\rho}, 0\right\} .
$$

Using (11) and (16), the policy maker's objective function is

$$
V^{C}\left(g_{a}, g_{b}, \pi_{\alpha}, \pi_{\beta}\right)=\mu \mathcal{W}+(1-\mu)\left(S_{\alpha}+S_{\beta}\right) .
$$

The parameter $\mu, 0<\mu \leq 1$, captures the degree of "benevolence" of the policy maker. We rule out the unrealistic case that the politician cares about contributions only, i.e. we assume $\mu \neq 0$.

By solving the lobbying game through the maximization of (17), the optimal public good supply, both for $g_{a}$ and $g_{b}$, is ${ }^{5}$

$$
\tilde{g}^{C}=\hat{g}^{C}+2 m\left(h^{2}+f^{2}\right),
$$

where

$$
m=\frac{1-\mu}{\mu} .
$$

\footnotetext{
${ }^{5}$ We refer the reader to Appendix A for all the analytical details. Notice that throughout the paper a "hat" denotes the solutions obtained without lobbying, whereas a "tilde" denotes the corresponding solutions under lobbying for public good provision.
} 
Unsurprisingly, lobbying induces an upward distortion in public good supply, and hence a welfare loss, unless the policy maker is fully benevolent $(\mu=1)$.

Equilibrium net profits and contributions are

$$
\begin{aligned}
& \tilde{\pi}^{C}=\hat{\pi}^{C}+m\left(h^{4}+f^{4}+4 h^{2} f^{2}\right), \\
& \tilde{s}^{C}=m\left(h^{4}+f^{4}\right) .
\end{aligned}
$$

Eq. (20) shows that profits under lobbying are equal to profits without it, $\hat{\pi}^{C}$, plus a profit gain from lobbying. As expected, if the policy maker does not care about lobbyists' contributions, $\tilde{\pi}^{C}=\hat{\pi}^{C}$ and $\tilde{s}^{C}=0$, since $m=0$.

The lobbying game in which both firms lobby for both public goods is not the only one conceivable. In fact, each firm has four options - lobby for both public goods, lobby for one public good only (either the one produced in its own region or the one produced in the other region), and no lobby. However, we do not need to examine all the corresponding lobbying games, since each firm's profits are larger if it lobbies for both public goods, no matter what the other firm does. This follows directly from the definition of truthful strategy and the associated compensating contribution function. From proposition 2 in Dixit et al. (1997), a truthful strategy is weakly dominant, and in our setting truthful strategies always involve non-negative contributions by both firms on both public goods.

\subsection{Decentralization}

Under decentralization, each firm has four possible strategies: lobby both regions $(B)$, lobby only "at home" - inside its region $(I)$, lobby only "abroad" — outside its region $(O)$, and, finally, no lobby $(N)$. This strategy set gives rise to a $4 \times 4$ normal form symmetric game - that we denote as the where-to-lobby game - whose payoffs are the firms' equilibrium profits at the corresponding truthful equilibrium of the lobbying-game. By symmetry between firms, it is sufficient to consider 9 different lobby games only to construct the where-to-lobby game (in addition to the no-lobby case already examined in section 3). In the following we focus on those lobbying games in which firms play the same strategy, referring the reader to Appendix A for all remaining cases.

Let $S_{\rho r}\left(g_{r}, \pi_{\rho r}\right)$ be the compensating contribution schedule that firm $\rho$ offers the policy maker of region $r$, where $S_{\alpha a}=\max \left\{h^{2} g_{a}-\pi_{\alpha a}, 0\right\}, S_{\beta a}=\max \left\{f^{2} g_{a}-\pi_{\beta a}, 0\right\}, S_{\alpha b}=$ $\max \left\{f^{2} g_{b}-\pi_{\alpha b}, 0\right\}$ and $S_{\beta b}=\max \left\{h^{2} g_{b}-\pi_{\beta b}, 0\right\}$. When both firms lobby both regions $(B B)$, policy makers maximize ${ }^{6}$

$$
\begin{aligned}
& V_{a}^{D B B}=\mu\left(W_{a}-S_{\alpha b}+S_{\beta a}\right)+(1-\mu)\left(S_{\alpha a}+S_{\beta a}\right), \\
& V_{b}^{D B B}=\mu\left(W_{b}-S_{\beta a}+S_{\alpha b}\right)+(1-\mu)\left(S_{\beta b}+S_{\alpha b}\right) .
\end{aligned}
$$

As already noted above, under decentralization, different lobbies' contributions do not have the same weight into the local politicians' preferences. One unit of contribution a firm makes abroad counts as $-\mu$ in the home region but as 1 in the recipient region, while one unit of contribution a firm makes at home counts as $1-\mu$ in the home region and nothing abroad.

\footnotetext{
${ }^{6}$ We assume that the degree of benevolence of regional policy makers is the same as that of the central policy maker.
} 
The optimal public good supply in each region is (see Appendix A for details)

$$
\tilde{g}^{D B B}=\hat{g}^{D}+2 f^{2}+2 m\left(h^{2}+f^{2}\right),
$$

and total (home plus abroad) net profits of each firm are

$$
\tilde{\pi}^{D B B}=\hat{\pi}^{D}+m h^{4}+2(1+2 m) h^{2} f^{2}+\left(m-m^{-1}\right) f^{4} .
$$

In a decentralized system lobbies are able to influence public policy even when the social planner is fully benevolent $(\mu=1)$. In fact, even if the regional policy maker does not place any value on contributions per se, contributions offered by the foreign firm enter the region social welfare and hence influence her choices, as represented by the second term in (24).

Turning to the case in which both firms lobby their home region only $(I I)$, the policy makers' objective functions become

$$
\begin{aligned}
& V_{a}^{D I I}=\mu W_{a}+(1-\mu) S_{\alpha a}, \\
& V_{b}^{D I I}=\mu W_{b}+(1-\mu) S_{\beta b},
\end{aligned}
$$

and, as it is shown in Appendix A, public good supply and total net profits are, respectively,

$$
\begin{aligned}
& \tilde{g}^{D I I}=\hat{g}^{D}+2 m h^{2}, \\
& \tilde{\pi}^{D I I}=\hat{\pi}^{D}+m h^{4}+2 m h^{2} f^{2} .
\end{aligned}
$$

Finally, when both firms lobby only abroad $(O O)$, policy makers maximize

$$
\begin{aligned}
& V_{a}^{D O O}=\mu\left(W_{a}-S_{\alpha b}+S_{\beta a}\right)+(1-\mu) S_{\beta a}, \\
& V_{b}^{D O O}=\mu\left(W_{b}-S_{\beta a}+S_{\alpha b}\right)+(1-\mu) S_{\alpha b},
\end{aligned}
$$

obtaining

$$
\tilde{g}^{D O O}=\hat{g}^{D}+2(1+m) f^{2},
$$

and thus total net profits are

$$
\tilde{\pi}^{D O O}=\hat{\pi}^{D}+2(1+m) h^{2} f^{2}+(1+m) f^{4} .
$$

Using (25), (29) and (33), as well as the other expressions for equilibrium profits in Table 3, Appendix A, the resulting where-to-lobby game is shown in Table 1. Each cell contains the payoff of the row player, firm $\alpha$, at the top, and that of the column player, firm $\beta$, at the bottom. The profit gains from lobbying of the firm playing strategy $i$ when the opponent is playing $j$, with $i, j \in\{B, I, O, N\}$ are denoted with $\Delta \pi^{i j}=\tilde{\pi}^{D i j}-\hat{\pi}^{D}$.

As illustrated in Figure 1, the equilibria of the where-to-lobby game depend on the parameter $\mu$, representing politicians' preferences for contributions, and on the differentialcost parameter $\delta$, which influences market structure. The thick curves divide the closed set $\mathcal{S}=(\mu, \delta) \in[0,1] \times\left[1, \delta_{\max }\right]$ into three subsets,${ }^{7}$ one in which the unique Nash equilibrium of the where-to-lobby game is $B B$, one in which it is $I I$, and finally one in which it is $O O$. Firms lobby both policy makers only if the latter are "greedy" enough, assigning at least as much weight to contributions as to social welfare (i.e. $\mu \leq \frac{1}{2}$ ). On the other hand, if politicians care more about social welfare than contributions, firms lobby at most one politician. Whether it is the home one (equilibrium $I I$ ) or the outside one (equilibrium $O O)$, it depends on the values of $\delta$ and $\mu$. Proposition 2 makes this argument precise.

\footnotetext{
${ }^{7}$ The meaning of the curves $\mu^{E}(\delta ; c)$ and $\mu^{S}(\delta ; c)$, will become apparent in Corollary 1 and Proposition 3 , respectively.
} 
Table 1: The where-to-lobby game under decentralization

\begin{tabular}{|c|c|c|c|c|c|}
\hline & \multicolumn{4}{|c|}{ firm $\beta$} \\
\hline & & B & I & $\mathrm{O}$ & $\mathrm{N}$ \\
\hline \multirow{4}{*}{$\begin{array}{l}\mathrm{f} \\
\mathrm{i} \\
\mathrm{r} \\
\mathrm{m} \\
\alpha\end{array}$} & B & $\begin{array}{c}\Delta \pi^{B B}=m h^{4}+2(1+2 m) h^{2} f^{2}+ \\
+\left(m-m^{-1}\right) f^{4}, \\
m h^{4}+2(1+2 m) h^{2} f^{2}+ \\
+\left(m-m^{-1}\right) f^{4}=\Delta \pi^{B B}\end{array}$ & $\begin{array}{r}\Delta \pi^{B I}=m h^{4}+2 m h^{2} f^{2}+ \\
+\left(m-m^{-1}\right) f^{4}, \\
m h^{4}+2(1+2 m) h^{2} f^{2}=\Delta \pi^{I B}\end{array}$ & $\begin{array}{r}\Delta \pi^{B O}=m h^{4}+2(1+m) h^{2} f^{2}+ \\
+\left(m-m^{-1}\right) f^{4}, \\
2(1+2 m) h^{2} f^{2}+(1+m) f^{4}=\Delta \pi^{O B}\end{array}$ & $\begin{array}{r}\Delta \pi^{B N}=m h^{4}+\left(m-m^{-1}\right) f^{4}, \\
2(1+2 m) h^{2} f^{2}=\Delta \pi^{N B}\end{array}$ \\
\hline & I & $\begin{array}{l}\Delta \pi^{I B}=m h^{4}+2(1+2 m) h^{2} f^{2} \\
\begin{aligned} m h^{4}+2 m h^{2} f^{2}+ \\
\quad+\left(m-m^{-1}\right) f^{4}=\Delta \pi^{B I}\end{aligned}\end{array}$ & $\begin{aligned} \Delta \pi^{I I}= & m h^{4}+2 m h^{2} f^{2} \\
& m h^{4}+2 m h^{2} f^{2}=\Delta \pi^{I I}\end{aligned}$ & $\begin{aligned} \Delta \pi^{I O}= & m h^{4}+2(1+m) h^{2} f^{2}, \\
& 2 m h^{2} f^{2}+(1+m) f^{4}=\Delta \pi^{O I}\end{aligned}$ & $2 m h^{2} f^{2}=\Delta \pi^{N I}$ \\
\hline & $\mathrm{O}$ & $\begin{array}{l}\Delta \pi^{O B}=2(1+2 m) h^{2} f^{2}+(1+m) f^{4} \\
\begin{aligned} m h^{4}+2(1+ & m) h^{2} f^{2}+ \\
& \quad+\left(m-m^{-1}\right) f^{4}=\Delta \pi^{B O}\end{aligned}\end{array}$ & $\begin{array}{l}\Delta \pi^{O I}=2 m h^{2} f^{2}+(1+m) f^{4} \\
m h^{4}+2(1+m) h^{2} f^{2}=\Delta \pi^{I O}\end{array}$ & $\begin{array}{l}\Delta \pi^{O O}=2(1+m) h^{2} f^{2}+(1+m) f^{4}, \\
2(1+m) h^{2} f^{2}+(1+m) f^{4}=\Delta \pi^{\infty O}\end{array}$ & $\begin{aligned} \Delta \pi^{O N}= & (1+m) f^{4}, \\
& 2(1+m) h^{2} f^{2}=\Delta \pi^{N O}\end{aligned}$ \\
\hline & $\mathrm{N}$ & $\begin{aligned} \Delta \pi^{N B}= & 2(1+2 m) h^{2} f^{2} \\
& m h^{4}+\left(m-m^{-1}\right) f^{4}=\Delta \pi^{B N}\end{aligned}$ & $\begin{aligned} \Delta \pi^{N I}=2 m h^{2} f^{2} & \\
& m h^{4}=\Delta \pi^{I N}\end{aligned}$ & $\begin{aligned} \Delta \pi^{N O}=2(1+m) h^{2} f^{2} & \\
& (1+m) f^{4}=\Delta \pi^{O N}\end{aligned}$ & 0 \\
\hline
\end{tabular}




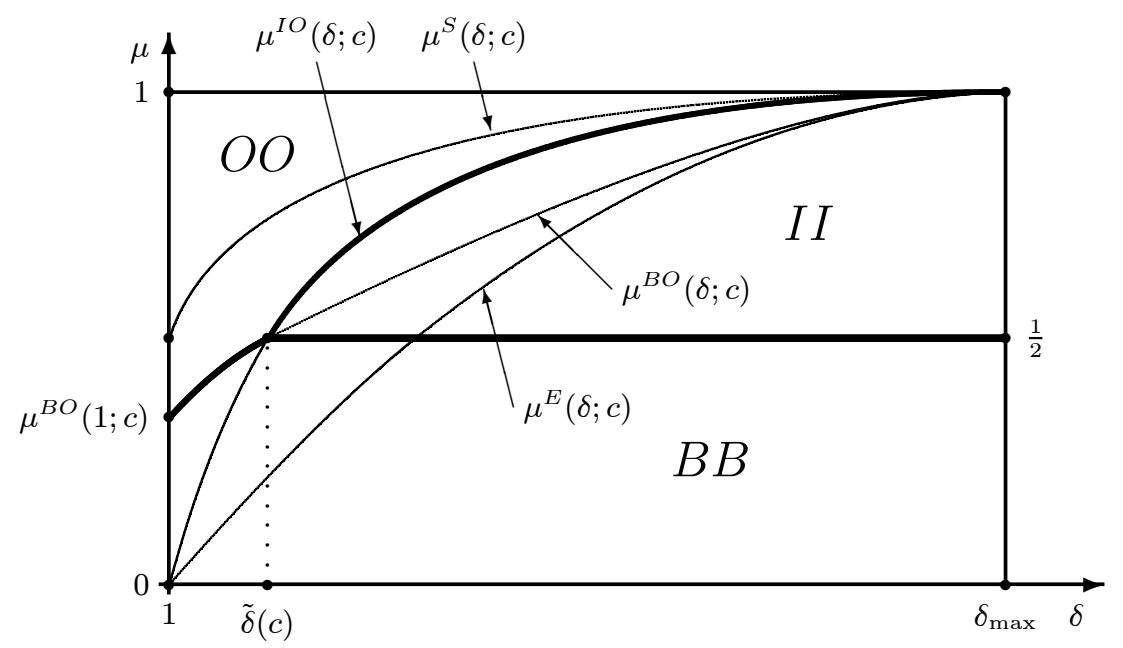

Figure 1: Lobbying equilibria under decentralization

Proposition 2 For $\delta \in[1, \tilde{\delta}]$ the unique Nash equilibrium of the where-to-lobby game under decentralization is $B B$ if and only if $\mu \in\left(0, \mu^{B O}\right]$ and $O O$ otherwise. For $\delta \in$ $\left(\tilde{\delta}, \delta_{\max }\right]$ the equilibrium is $B B$ if and only if $\mu \in\left(0, \frac{1}{2}\right], I I$ if and only if $\mu \in\left(\frac{1}{2}, \mu^{I O}\right]$ and $O O$ otherwise, where $\mu^{B O}(\tilde{\delta} ; c)=\mu^{I O}(\tilde{\delta} ; c)=\frac{1}{2}$, and

$$
\begin{aligned}
& \mu^{B O}(\delta ; c)=1-\frac{\left(\sqrt{4 h^{4}+f^{4}}-f^{2}\right) f^{2}}{2 h^{4}}, \\
& \mu^{I O}(\delta ; c)=\frac{h^{4}-f^{4}}{h^{4}},
\end{aligned}
$$

and

$$
\tilde{\delta}(c)=\frac{(2+\sqrt[4]{2}) c+\sqrt[4]{2}-1}{(1+2 \sqrt[4]{2}) c}
$$

Proof. See Appendix A.

While under centralization firms always lobby for both public goods, Proposition 2 shows that under decentralization this result does not emerge if politicians are benevolent enough (i.e. $\mu>\frac{1}{2}$ ). The intuition is that when a firm lobbies abroad, the contribution paid to the politician counts as a welfare loss at home. Hence, in order to successfully lobby at home as well, the firm has to pay a "double" bribe: one to compensate for the welfare loss of lobbying abroad, and one to compensate for the resulting public good distortion at home. Double lobbying turns out to be profitable only if $\mu<\frac{1}{2}$, since it is not necessary, coeteris paribus, to pay high contributions to successfully lobby greedy politicians. On the contrary, when firms face politicians who are benevolent enough, it becomes too costly to compensate the home politician for the negative externality caused by lobbying abroad, and hence it becomes profitable to lobby at most in one region. ${ }^{8}$ When this is the case,

\footnotetext{
${ }^{8}$ This intuition is evident from the equilibrium contributions shown in Table 4. A firm, say $\alpha$, lobbying both regions pays a contribution $\tilde{s}_{\alpha b}^{D B B}=(1+m) f^{4}$ to the abroad politician. The contribution paid at home, $\tilde{s}_{\alpha a}^{D B B}$, is made up of two terms: $\left(1+m^{-1}\right) f^{4}$ as a compensation for the welfare loss for paying contributions abroad, and $m h^{4}$ as a compensation for public good distortion at home. Clearly, if $\left(1+m^{-1}\right) f^{4}>(1+m) f^{4}$, which occurs if $\mu>\frac{1}{2}$, it does not pay to lobby both regions.
} 
whether the equilibrium is $I I$ or $O O$ hinges upon two contrasting effects. On the one hand, since the weight assigned by the politician to contributions from the home firms is lower than the one assigned to contributions from abroad ( $1-\mu$ and 1 , respectively), firms have an advantage in lobbying abroad. On the other hand, since a firm is more productive at home, i.e. $h \geq f$, it makes more profits when lobbying at home. These two contrasting effects - i.e. the fact that the comparative advantage of lobbying abroad is increasing in $\mu$ whereas that of lobbying at home is increasing in $\delta$ - explain why the boundary between the equilibria $O O$ and $I I$ is given by the increasing function $\mu^{I O}(\delta ; c)$.

It is also worth noting that the equilibria of the where-to-lobby game are not always Pareto efficient in terms of aggregate firms' net profits. As Corollary 1 shows, when the equilibrium is either $B B$ or $O O$ aggregate firms' profits are maximized. On the contrary, when the equilibrium is $I I$ firms may end up in a prisoner dilemma, in which they both lobby at home while lobbying abroad would be more profitable. As shown in Figure 1, the boundary between the efficient Nash equilibria $I I$ and the inefficient ones is given by the curve $\mu^{E}(\delta ; c)$, with the former equilibria lying below the curve.

Corollary 1 The Nash equilibria $B B$ and $O O$ of the where-to-lobby game are Pareto efficient in terms of aggregate firms' net profits. The equilibrium II is Pareto efficient if and only if, for $\delta \in\left(\tilde{\delta}, \delta_{\max }\right], \mu \in\left(\frac{1}{2}, \max \left\{\mu^{E}, \frac{1}{2}\right\}\right]$, where $\mu^{E}(\delta ; c)=\frac{h^{4}-f^{4}}{h^{4}+2 h^{2} f^{2}}$. Otherwise II is Pareto dominated by the strategy pair $O O$.

\section{Proof. See Appendix A.}

\subsection{A comparison}

The above results allow for a comparison of lobbying behavior under centralization and decentralization along various dimensions: social welfare and public good supply, firms' net profits, and contributions to politicians. From Proposition 1 we know that in a world without lobbying aggregate social welfare is higher under centralization than under decentralization, since under the latter regime regional policy makers do not internalize as social welfare the profits of the foreign firm and hence undersupply public goods.

This result is reversed when lobbies influence the policy making process. In a centralized system, since both firms lobby for both public goods and the policy maker internalizes all spillover effects on profits, the resulting upward distortion in public good supply reduces social welfare. When the equilibrium is $B B$ the same distortion, however, occurs under decentralization too, as the supply of public goods is the same under decentralization and centralization. The joint lobbying effort exerted by firms on both regional policy makers induces the latter to implicitly account for the regional profit-spillovers via in public good supply. However, when politicians are benevolent enough and firms lobby at most one policy maker (i.e. when the equilibrium is either $I I$ or $O O$ ) lobbying is less effective and the distortion in public good supply and the associated welfare loss are lower under decentralization than under centralization. Moreover, lobbies always prefer a centralized system over a decentralized one, since net profits are higher. This is obvious if the decentralized equilibrium is $B B$, since gross profits are the same under the two regimes whereas contributions are higher under decentralization than under centralization. Firms are also clearly better off under centralization whenever the equilibrium under decentralization is either $I I$ or $O O$, since in the latter case gross profits are lower while contributions, though smaller in some cases, do not allow higher net profits compared to centralization.

The following proposition summarizes these results. 
Proposition 3 In the presence of lobbying, firms' net profits are higher under centralization than under decentralization. Contributions to politicians are higher under decentralization when the equilibrium is $B B$ and, provided that $\mu>\mu^{S}(\delta ; c)=\frac{h^{4}}{h^{4}+f^{4}}$, also when the equilibrium is OO; otherwise contributions are higher under centralization. Public good supply and aggregate social welfare are the same under the two regimes when the equilibrium under decentralization is BB. When the equilibrium is either II or OO, public good supply is lower, whereas aggregate social welfare is higher, under decentralization than under centralization.

Proof. See Appendix A.

\section{$5 \quad$ Lobbying for the market}

We consider now a different political economy framework, one in which firms lobby for acquiring the right to enter the market instead of lobbying for public goods provision. We assume the following time line. In stage 1, the government (central or regional, depending on the case) decides on the number of firms that are allowed to operate in the market for good $x$. If both firms are allowed to enter, firms have no incentive to pay the politician in stage 2 since we do not allow in this section for lobbying in the market ex post for public good provision (hence the game goes directly to stage 4). Conversely, if the government allows for one entrant only in stage 1, in stage 2 firms competing for the market make a credible commitment to pay politicians a contribution if they are given the monopoly right in the market for good $x$. In stage 3 , the politician, knowing the offer made by the firms in stage 2, assigns the monopoly right to the firm that guarantees her the highest payoff (weighted average of social welfare and lobbies' contributions) and cashes the contribution. In stage 4 , the government chooses public good supply by maximizing social welfare. Finally, in stage 5 market equilibrium is determined along the lines of section 2 . The model is solved by backward induction.

The more complex structure of this case allows us to consider three different institutional settings. In the first one, the central government chooses both the number of firms entering each regional market and local public good supplies (full centralization). In the second one, the central government establishes the number of firms that are allowed to operate in each regional market but regional public good supply is decided at the regional level (split competencies). Finally, in the third case, each regional government chooses both the number of firms entering its market and public good supply (full decentralization). The case of split competencies captures the well known fact that in most countries regional and central competencies often overlap (e.g. competition policies), rather than being neatly assigned to one of the two levels of governments. Thus, this allows us to ask if the presence of lobbying may provide a rationale for these arrangements.

To investigate these three cases, we need to compute first market equilibrium and welfare under monopoly (stage 5), thus integrating the duopoly analysis already provided in section 2. Letting

$$
H=\frac{1-c}{2} \text { and } \quad F=\frac{1-\delta c}{2},
$$

by standard profit maximization, when the regional markets are monopolized the equilibrium quantities are $x_{a}^{*}=H g_{a}$ and $x_{b}^{*}=H g_{b}\left(x_{a}^{*}=F g_{a}\right.$ and $\left.x_{b}^{*}=F g_{b}\right)$ if it is the home (foreign) firm that supplies the market. The corresponding equilibrium profits are 
$\Pi_{\alpha}^{*}=H^{2} g_{a}$ and $\Pi_{\beta}^{*}=H^{2} g_{b}\left(\Pi_{\alpha}^{*}=F^{2} g_{b}\right.$ and $\left.\Pi_{\beta}^{*}=F^{2} g_{a}\right)$ when the home (foreign) firm supplies the market.

Focusing again on region $a$, and depending on which firm operates in each region, social welfare is

$$
\begin{aligned}
W_{a}^{H_{a} H_{b}} & =\frac{3 H^{2} g_{a}}{2}-\frac{g_{a}^{2}}{4}+\bar{y} \\
W_{a}^{F_{a} F_{b}} & =\frac{F^{2} g_{a}+2 F^{2} g_{b}}{2}-\frac{g_{a}^{2}}{4}+\bar{y} \\
W_{a}^{H_{a} F_{b}} & =\frac{3 H^{2} g_{a}+2 F^{2} g_{b}}{2}-\frac{g_{a}^{2}}{4}+\bar{y} \\
W_{a}^{F_{a} H_{b}} & =\frac{F^{2} g_{a}}{2}-\frac{g_{a}^{2}}{4}+\bar{y}
\end{aligned}
$$

where the apix $H_{a} H_{b}$ (resp. $F_{a} F_{b}$ ) denotes that home (resp. foreign) firms are monopolists in both regions, and $H_{a} F_{b}$ (resp. $F_{a} H_{b}$ ) that firm $\alpha$ (resp. $\beta$ ) is a monopolist in both regions. We begin the analysis with the full centralization case.

\subsection{Full centralization}

By symmetry, we only consider the case in which the central government opts in stage 1 for the same policy, one or two firms, in both regions. Suppose first that the government allows for both firms supplying both regional markets. This case has already been studied in section 3, where policy without lobbying was described. Substituting the optimal public good provision given in (12) into (11), the politician's value function when both firms are allowed to enter the market is then

$$
\hat{V}^{h f}=\mu \frac{\left[(h+f)^{2}+2\left(h^{2}+f^{2}\right)\right]^{2}}{2}+2 \mu \bar{y} .
$$

Consider next the case in which only one firm is allowed to enter the regional markets. The government holds simultaneously an auction for each market, and firms have now an incentive to compete for it, making contributions to the government. Let $S_{\rho}^{H}$ and $S_{\rho}^{F}$ be the contribution offered by firm $\rho$ for serving the home and the foreign market, respectively. The following Lemma summarizes the outcome of firms' competition for the market.

Lemma 1 Under full centralization, if only one firm is allowed to enter the regional markets, then each firm gets the home market by paying the contribution

$$
\hat{S}_{\rho}^{H}=\max \left\{\hat{T}^{H}, 0\right\} \text {, where } \hat{T}^{H}=-\frac{9 \mu\left(H^{4}-F^{4}\right)}{4(1-\mu)}+3 F^{4} .
$$

The corresponding politician's value function is

$$
\hat{V}^{H}=\mu \frac{9 H^{4}}{2}+2(1-\mu) \hat{S}_{\rho}^{H}+2 \mu \bar{y} .
$$

Proof. See Appendix B.

The intuition is simple. A local monopoly is always more profitable than a foreign one, since by assumption the home firm has a cost advantage over the foreign one $(H \geq F)$ and the optimal public good supply is higher when the home firm serves the market. Hence 


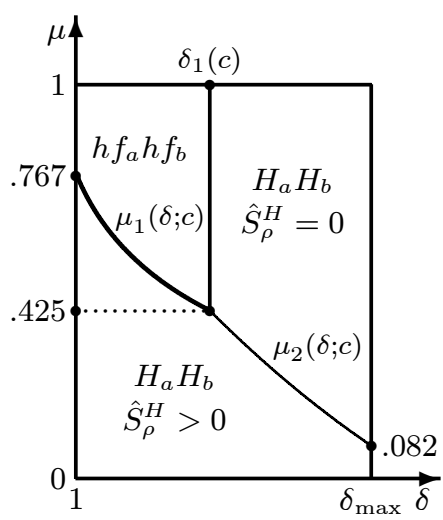

(a)

Full centralization

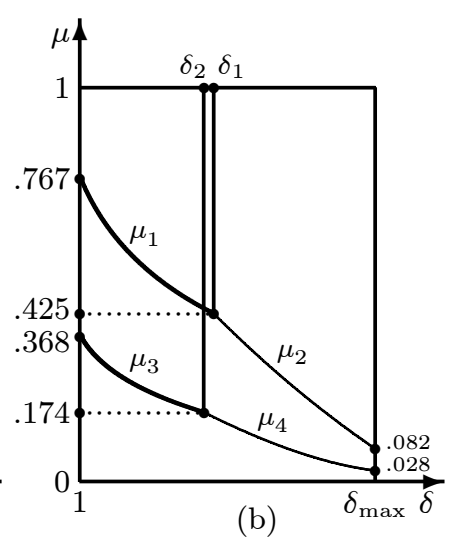

Full centralization versus Split competencies

Figure 2: Lobbying for the market

each firm wins the home market by outbidding the foreign firm, whose offer $\hat{S}_{\rho}^{F}$ at most equals the profits it would make by serving the foreign market in a monopolistic regime, $3 F^{4}$. Notice however from (43) that the home firm does not need to offer that much, and in some cases it does not even need to make a positive offer to win the market. The reason is that if the foreign firm gets the market, then a welfare loss is observed compared to a home-monopoly. Thus, in order to win the market, the home firm can always offer the politician a lower contribution than the one offered by the foreign firm. Quite intuitively, the higher are $\mu$ and $\delta$ the more likely is that the home firm does not need to make a positive offer to win the market.

By comparing (42) and (44), we can finally characterize the central government's choice in stage 1.

Proposition 4 Under full centralization, for $\delta \in\left[1, \delta_{1}\right], \delta_{1}(c)=\frac{5+17 c}{22 c}$, there exists a $\mu_{1}(\delta ; c)$, decreasing in $\delta$, such that for all $\mu \leq \mu_{1}$ only one firm is allowed to enter each regional market; by Lemma 1, the home firm obtains a monopoly upon the payment of a contribution. For $\delta \in\left[1, \delta_{1}\right]$ and $\mu>\mu_{1}$ both firms are allowed into both regional markets. For $\delta \in\left(\delta_{1}, \delta_{\max }\right]$ only one firm is allowed to enter each regional market for all $\mu$ and therefore the home firm gets a monopoly. As for contributions, there exists a $\mu_{2}(\delta ; c)$, decreasing in $\delta$, such that the firm pays a contribution for all $\mu<\mu_{2}$ and no contribution otherwise.

Proof. See Appendix B.

The results in Proposition 4 are illustrated in Figure 2-a. For $\delta \leq \delta_{1}$ and $\mu>\mu_{1}$ the policy maker opts for a duopoly in both markets $\left(h f_{a} h f_{b}\right)$. In all other cases she opts for a monopoly and, given the results in Lemma 1 , each firm wins its home market $\left(H_{a} H_{b}\right)$. In this latter case, positive contributions $\left(\hat{S}_{\rho}^{H}>0\right)$ are paid if and only if $\mu$ is below a given threshold ( $\mu_{1}$ or $\mu_{2}$, depending on the value of $\delta$ ); otherwise the home firm does not need to offer a contribution to gain access to the monopolized market.

To understand the intuition behind these results, suppose first that the politician simply maximizes social welfare (i.e. $\mu=1$ ). The proposition then shows that there exists a threshold level of the cost advantage for the home firm, $\delta_{1}$, such that for $\delta<\delta_{1}\left(\delta \geq \delta_{1}\right)$, social welfare is higher (lower) under a duopoly than under a monopoly. Hence, the fully benevolent politician simply lets both firms enter both markets in the former case and 
only the home firm in the latter one. If instead $\mu<1$, the politician faces a trade-off when $\delta<\delta_{1}$. By creating a monopoly, she gets a contribution from the home firm winning the contest for the market, but at the cost of the monopoly welfare loss; however, if she lets both firms in, she avoids this welfare cost but does not get any contributions (recall there is no lobbying in the market here). This explains why, for $\delta<\delta_{1}$, a sufficiently benevolent policy maker - one with preferences $\mu>\mu_{1}$ - makes the efficient choice, while a politician who is greedier $\left(\mu \leq \mu_{1}\right)$ prefers a monopoly by home firms in each regional market. This trade off is absent when $\delta \geq \delta_{1}$, since social welfare is however higher under a home monopoly than under a duopoly. Hence the politician always allows only one firm in each market, no matter her degree of benevolence. The latter only bears on whether contributions are paid to the central politician. If $\mu>\mu_{2}$, i.e. if the politician is sufficiently benevolent, then home firms would not need to bribe the politician in order to win the local monopoly, even though foreign firms made a positive offer. Instead, if the politician is greedy $\left(\mu \leq \mu_{2}\right)$, the home firm must offer a contribution to outbid the offer made by the foreign firm. Recalling that lobbies' contributions are pure transfers and that when lobbying is for the market there are no distortions in public goods supply, we can conclude that a loss in social welfare occurs if and only if lobbying induces the central government to opt for local monopolies whenever a benevolent social planner would have opted for local duopolies. Formally:

Corollary 2 Under full centralization lobbying causes a welfare loss iff $\delta \in\left[1, \delta_{1}\right)$ and $\mu \in\left(0, \mu_{1}\right)$.

\subsection{Split competencies}

Consider next the case in which the central government chooses how many firms enter each market, but the regional governments choose public good supply. Since what differentiates split competencies and the fully centralized regimes is only the equilibrium level of public goods supply, we can directly follow the above logic to prove: ${ }^{9}$

Proposition 5 Under split competencies, for $\delta \in\left[1, \delta_{2}\right], \delta_{2}(c)<\delta_{1}(c)$ for all $c \in(0,1)$, there exists a $\mu_{3}(\delta ; c)$ such that for all $\mu \leq \mu_{3}$ only one firm is allowed to enter each regional market, and therefore the home firm obtains a monopoly upon the payment of a contribution; otherwise both firms are allowed into both regional markets. For $\delta \in\left(\delta_{2}, \delta_{\max }\right]$ only one firm is allowed to enter each regional market for all $\mu$, and hence the home firm gets a monopoly. As for contributions, there exists a $\mu_{4}(\delta ; c)$ such that the firm pays a contribution for all $\mu<\mu_{4}$ and no contribution otherwise.

Split competencies and full centralization are compared in Figure 2-b. Notice that the area in which each firm obtains a monopoly at home upon the payment of a contribution is certainly smaller under split competencies, since the curves $\mu_{3}$ and $\mu_{4}$ for the latter case lie below the respective curves $\mu_{1}$ and $\mu_{2}$ for centralization. Hence, lobbying for the market is less effective under split competencies than under centralization.

However, the comparison in terms of social welfare depends on parameters. As $\delta_{2}<\delta_{1}$, there is an area under split competencies - defined by $\delta \in\left(\delta_{2}, \delta_{1}\right)$ and $\mu>\mu_{1}$ - in which even a fully benevolent central politician $(\mu=1)$ would opt for a monopoly by the home firm instead of the more efficient duopoly. This is so because under split competencies

\footnotetext{
${ }^{9}$ The formal proof is available from the authors upon request.
} 


\begin{tabular}{|c|c|c|c|}
\hline & \multicolumn{2}{|l|}{ region $b$} \\
\hline & & two firms & one firm \\
\hline e & $\begin{array}{l}\text { two } \\
\text { firms }\end{array}$ & $\hat{V}_{a}^{h f}=\mu \frac{\left[(h+f)^{2}+2 h^{2}\right]\left[(h+f)^{2}+2\left(h^{2}+f^{2}\right)\right]}{4}$ & $\hat{V}_{a}^{h f_{a} H_{b}}=\mu \frac{\left[(h+f)^{2}+2 h^{2}\right]^{2}}{4}$ \\
\hline g. & one & $\begin{array}{l}\hat{V}_{a}^{h f_{a} H_{b}}= \\
=\left\{\begin{array}{l}\frac{4 f^{2}\left[(h+f)^{2}+2 h^{2}\right] \mu+(4+\mu) F^{4}}{4} \text { if } \mu<\mu_{5}(\delta ; c), \\
\mu \frac{9 H^{4}+4 f^{2}\left[(h+f)^{2}+2 h^{2}\right]}{4} \text { otherwise. }\end{array}\right.\end{array}$ & $\begin{array}{l}\hat{V}_{a}^{H_{a} H_{b}}= \\
=\left\{\begin{array}{l}\frac{F^{4}}{4}(4+\mu) \text { if } \mu<\mu_{5}(\delta ; c), \\
\frac{9 H^{4}}{4} \mu \text { otherwise. }\end{array}\right.\end{array}$ \\
\hline
\end{tabular}

Table 2: Politicians' value functions under full decentralization

public good provision is decided at the local level and as shown above (in section 3) local public goods are underprovided by local governments in local duopolies (since local governments do not count profits from foreign firms as social welfare). Hence, allowing for a single home producer by the center is a way to partly counteract this inefficiency at local level. On the other hand, split competencies is more efficient than centralization for $\delta<\delta_{2}$, as the set in which two firms are allowed in both markets (the efficient choice) is larger under split competencies than under centralization, since $\mu_{3}<\mu_{1}$. This is again due to the fact that local governments do not consider foreign firms' profits as part of the (local) social welfare. In fact, in the event of a foreign monopoly, a local government undersupplies the public good compared to a central government. This means that, under split competencies, in order to outbid the foreign competitor home firms need to offer the politician a smaller contribution, which explains why lobbying is more effective under full centralization.

\subsection{Full decentralization}

We finally consider the case of full decentralization, in which regional governments (simultaneously) choose first the number of firms that are allowed to enter their market, and then public good supply. The choice on the number of firms gives rise to a $2 \times 2$ normal form game between regional policy makers. Whenever only one firm is allowed to supply a regional market firms compete to gain access to it by bribing the regional policy maker. For any strategy pair, Lemma 2 establishes the outcome of firms' competition for the market and regional payoffs, shown in Table 2, in terms of the maximum value of politicians' objective functions. ${ }^{10}$

Lemma 2 Under full decentralization, whenever a region allows only for one firm to serve its local market, then it is the home firm to gain access to the market, paying the contribution

$$
\hat{S}_{\rho}^{H}=\max \left\{-\frac{\mu\left(9 H^{4}-F^{4}\right)}{4(1-\mu)}+\frac{F^{4}}{1-\mu}, 0\right\}
$$

to the politician.

Depending on the number of firms allowed into each regional markets, politicians' value functions are those shown in Table 2.

\footnotetext{
${ }^{10}$ Since the game is symmetric, the Table shows only the payoffs of region $a$ 's politician. Also, to save space, regional social welfare is net of the endowment $\bar{y}$.
} 
Proof. See Appendix B.

The reasons why, under decentralization, it is always the home firm to gain a monopoly in its market when competing with the foreign firm, are the same already discussed for the other two regimes. From (45) it is immediate to see that $\hat{S}_{\rho}^{H}>0$ if and only if

$$
\mu<\mu_{5}(\delta ; c)=\frac{4 F^{4}}{9 H^{4}-F^{4}} .
$$

Regional politicians choose the number of firms in the market by playing the normal form game given in Table 2. The solution of such a policy game is given in the following proposition:

Proposition 6 Under full decentralization, it is a dominant strategy for both regional policy makers to admit only one firm in their market for all $\mu \in(0,1]$ and $\delta \in\left[1, \delta_{\max }\right]$. Hence, by Lemma 2 the home firm gets a local monopoly upon the payment of a positive contribution for $\mu<\mu_{5}(\delta ; c)$ and nothing otherwise.

Proof. See Appendix B.

Proposition 6 shows that lobbying for the market is most effective under full decentralization, with the home firms always gaining a local monopoly in their regional market. When $\delta<\delta_{1}$, although a duopoly would be the efficient solution in both regions, markets turn out to be fully monopolized no matter the value of $\mu$. This means that in the case of lobbying for the market full decentralization is the less efficient of the three regimes. Moreover, one can show that the Nash equilibrium (one-firm, one-firm) of the game in Table 2 is also Pareto inefficient in terms of politicians' aggregate value functions for all $\delta<\delta_{2}$. What makes the difference between full decentralization and split competencies is thus that, while under the former regime regional policy makers end up in a prisoner dilemma, under the latter regime this outcome does not occur, because it is the central policy maker that directly chooses the highest aggregate payoff along the diagonal cells of the game in Table 2 .

\section{Concluding remarks}

We began this work by recalling Prud'homme's argument against the dangers of decentralization due to lobbying effects by local interests. Our analysis made it clear when this argument is correct and when it is not. If firms lobby for the market, then decentralization is certainly a bad idea. Local governments have a strong incentive to allow only home firms to enter in the market, as their profits only matter for local welfare, which in turn means that a local firm can always easily outbid a foreign one. If firms lobby in the market, on the other hand, lobbying may not be as dangerous under decentralization as it is under centralization. Local governments do not internalize the spillover effects induced by foreign firms' profits, and while this may be a source of inefficiency for local public goods provision, it has the effect of making local governments more resilient to lobbies' contributions. This suggests that the best institutional structure as lobbying is concerned is one in which competencies across different levels of government are split, with central government taking care of decisions about the number of firms allowed to operate in the markets and local governments deciding on local public good production.

Our analysis could be extended in several directions. On the one hand, to better focus on the issue at hand, we abstracted from several realistic features of existing federations, 
such as intergovernmental transfers and firms mobility. Introducing these features may provide a more complete picture of the relationships between decentralization and lobbying. On the other hand, the political side of the model could be expanded, for instance by introducing campaign contributions to political parties and elections, as well as bargaining in legislatures. Allowing for a more complex institutional structure (along the lines, for example, of Persson and Tabellini, 2000, ch. 7, Mitra, 1999, Besley and Coate, 2001, Felli and Merlo, 2001) may highlight other channels of interaction between local interests and local policies.

\section{A Appendix: Lobbying for public good provision}

The lobbying-games are solved by extending the logic in proposition 3 in Dixit et al. (1997).

\section{A.1 Centralization}

From the first order conditions for maximizing (17),

$$
\mu \frac{\partial \mathcal{W}}{\partial g_{r}}+(1-\mu)\left(h^{2}+f^{2}\right)=0,
$$

we obtain $\tilde{g}^{C}$ in (18) for both $g_{a}$ and $g_{b}$. In deriving the first order condition (47), we ignore the non-negativity constraint on contributions, by letting $S_{\rho}=h^{2} g_{r}+f^{2} g_{-r}-\pi_{\rho}$ into the objective function, and then checking non-negativity ex post in the computed equilibrium. To compute the equilibrium profits of firm $\beta$ we need first to solve the problem in which firm $\alpha$ is lobbying and firm $\beta$ is not lobbying. Hence, the policy maker maximizes $V_{-\beta}^{C}=\mu \mathcal{W}+(1-\mu) S_{\alpha}$. From the corresponding first order conditions:

$$
\mu \frac{\partial \mathcal{W}}{\partial g_{a}}+(1-\mu) h^{2}=0, \quad \mu \frac{\partial \mathcal{W}}{\partial g_{b}}+(1-\mu) f^{2}=0,
$$

we obtain the optimal public good supplies:

$$
\tilde{g}_{a(-\beta)}^{C}=\hat{g}^{C}+2 m h^{2}, \quad \tilde{g}_{b(-\beta)}^{C}=\hat{g}^{C}+2 m f^{2} .
$$

Writing the equation $V^{C}\left(\tilde{g}_{a}^{C}, \tilde{g}_{b}^{C}, \pi_{\alpha}, \pi_{\beta}\right)=V_{-\beta}^{C}\left(\tilde{g}_{a(-\beta)}^{C}, \tilde{g}_{b(-\beta)}^{C}, \pi_{\alpha}\right)$ and solving for $\pi_{\beta}$, we obtain the equilibrium profits $\tilde{\pi}_{\beta}^{C}$ shown in (20). By symmetry, $\tilde{\pi}_{\alpha}^{C}=\tilde{\pi}_{\beta}^{C}$. Finally, by substituting (18) and (20) into (16), we check that equilibrium contributions in (21) are non-negative.

\section{A.2 Decentralization: derivation of the where-to-lobby game}

We solve the lobby game for each strategy pair occurring under decentralization, ignoring the non-negativity constraint on contributions, letting $S_{\alpha a}=h^{2} g_{a}-\pi_{\alpha a}, S_{\beta a}=f^{2} g_{a}-\pi_{\beta a}, S_{\alpha b}=$ $f^{2} g_{b}-\pi_{\alpha b}$ and $S_{\beta b}=h^{2} g_{b}-\pi_{\beta b}$. We check ex post that equilibrium contributions are non-negative. $V_{r}^{D i j}$ denotes the preferences of policy maker $r$ when firms $\alpha$ and $\beta$ are choosing action $i$ and $j$, respectively, $i, j \in\{B, I, O, N\}$. The results of the analysis are summarized in Table 3 (equilibrium profits) and Table 4 (equilibrium contributions).

\section{Both firms lobbying both regions $(B B)$}

When both firms lobby both regions, the policy makers' objective functions are (22) and (23) in the text. By maximizing (22) with respect to $g_{a}$ and (23) with respect to $g_{b}$, we obtain the symmetric solution $\tilde{g}^{D B B}$ in (24). To compute the equilibrium profits, assume that firm $\alpha$ lobbies both regions $(B)$ and firm $\beta$ does not lobby $(N)$. Policy makers maximize:

$$
\begin{aligned}
& V_{a}^{D B N}=\mu\left(W_{a}-S_{\alpha b}\right)+(1-\mu) S_{\alpha a}, \\
& V_{b}^{D B N}=\mu\left(W_{b}+S_{\alpha b}\right)+(1-\mu) S_{\alpha b} .
\end{aligned}
$$




\begin{tabular}{|ll|l|l|}
\hline & & $\begin{array}{l}\text { Profit at home } \\
h^{2} \hat{g}^{D}+\end{array}$ & $\begin{array}{l}\text { Profit abroad } \\
f^{2} \hat{g}^{D}+\end{array}$ \\
\hline firm $\rho$ & $B$ & $m h^{4}+2(1+m) h^{2} f^{2}-\left(1+m^{-1}\right) f^{4}$ & $(1+m) f^{4}+2 m h^{2} f^{2}$ \\
firm $-\rho$ & $B$ & $m h^{4}+2(1+m) h^{2} f^{2}-\left(1+m^{-1}\right) f^{4}$ & $(1+m) f^{4}+2 m h^{2} f^{2}$ \\
\hline firm $\rho$ & $B$ & $m h^{4}-\left(1+m^{-1}\right) f^{4}$ & $(1+m) f^{4}+2 m h^{2} f^{2}$ \\
firm $-\rho$ & $I$ & $m h^{4}+2(1+m) h^{2} f^{2}$ & $2 m h^{2} f^{2}$ \\
\hline firm $\rho$ & $B$ & $m h^{4}+2(1+m) h^{2} f^{2}-\left(1+m^{-1}\right) f^{4}$ & $(1+m) f^{4}$ \\
firm $-\rho$ & $O$ & $2(1+m) h^{2} f^{2}$ & $(1+m) f^{4}+2 m h^{2} f^{2}$ \\
\hline firm $\rho$ & $B$ & $m h^{4}-\left(1+m^{-1}\right) f^{4}$ & $(1+m) f^{4}$ \\
firm $-\rho$ & $N$ & $2(1+m) h^{2} f^{2}$ & $2 m h^{2} f^{2}$ \\
\hline firm $\rho$ & $I$ & $m h^{4}$ & $2 m h^{2} f^{2}$ \\
firm $-\rho$ & $I$ & $m h^{4}$ & $2 m h^{2} f^{2}$ \\
\hline firm $\rho$ & $I$ & $m h^{4}+2(1+m) h^{2} f^{2}$ & 0 \\
firm $-\rho$ & $O$ & 0 & $(1+m) f^{4}+2 m h^{2} f^{2}$ \\
\hline firm $\rho$ & $I$ & $m h^{4}$ & 0 \\
firm $-\rho$ & $N$ & 0 & $(1+m) f^{4}$ \\
\hline firm $\rho$ & $O$ & $2(1+m) h^{2} f^{2}$ & $(1+m) f^{4}$ \\
firm $-\rho$ & $O$ & $2(1+m) h^{2} f^{2}$ & $(1+m) f^{4}$ \\
\hline firm $\rho$ & $O$ & 0 & $N$ \\
firm $-\rho$ & $N$ & $2(1+m) h^{2} f^{2}$ & $\left(1+f^{2}\right.$ \\
\hline
\end{tabular}

Table 3: Firms' net profits under decentralization

\begin{tabular}{|ll|l|l|}
\hline & & Contributions at home & Contributions abroad \\
\hline firm $\alpha$ & $B$ & $\tilde{s}_{\alpha a}^{D B B}=m h^{4}+\left(1+m^{-1}\right) f^{4}$ & $\tilde{s}_{\alpha b}^{D B B}=(1+m) f^{4}$ \\
firm $\beta$ & $B$ & $\tilde{s}_{\beta b}^{D B B}=m h^{4}+\left(1+m^{-1}\right) f^{4}$ & $\tilde{s}_{\beta a}^{D B B}=(1+m) f^{4}$ \\
firm $\beta$ & $I$ & $\tilde{s}_{\beta b}^{D I B}=m h^{4}$ & - \\
firm $\beta$ & $O$ & - & $\tilde{s}_{\beta a}^{D O B}=(1+m) f^{4}$ \\
firm $\beta$ & $N$ & - & - \\
\hline firm $\alpha$ & $I$ & $\tilde{s}_{\alpha a}^{D I I}=m h^{4}$ & - \\
firm $\beta$ & $I$ & $\tilde{s}_{\beta b}^{D I I}=m h^{4}$ & - \\
firm $\beta$ & $O$ & - & $\tilde{s}_{\beta a}^{D O I}=(1+m) f^{4}$ \\
firm $\beta$ & $N$ & - & - \\
\hline firm $\alpha$ & $O$ & - & $\tilde{s}_{\alpha b}^{D O O}=(1+m) f^{4}$ \\
firm $\beta$ & $O$ & - & $\tilde{s}_{\beta a}^{D O O}=(1+m) f^{4}$ \\
firm $\beta$ & $N$ & - & - \\
\hline$\tilde{s}_{\rho r}^{D i j}$ denotes the equilibrium contribution made by firm $\rho$ in region $r$ when \\
firm $\alpha$ plays strategy $i$ and firm $\beta$ plays strategy $j$, where $i, j \in\{B, I, O, N\}$. \\
\hline
\end{tabular}

Table 4: Firms' contributions under decentralization 
Optimal public goods supplies are:

$$
\begin{aligned}
& \tilde{g}_{a}^{D B N}=\hat{g}^{D}+2 m h^{2}, \\
& \tilde{g}_{b}^{D B N}=\hat{g}^{D}+2(1+m) f^{2} .
\end{aligned}
$$

Solving

$$
\begin{aligned}
& V_{a}^{D B B}\left(\tilde{g}_{a}^{D B B}, \tilde{g}_{b}^{D B B}, \pi_{\alpha a}, \pi_{\beta a}, \pi_{\alpha b}\right)=V_{a}^{D B N}\left(\tilde{g}_{a}^{D B N}, \tilde{g}_{b}^{D B B}, \pi_{\alpha a}, \pi_{\alpha b}\right), \\
& V_{b}^{D B B}\left(\tilde{g}_{a}^{D B B}, \tilde{g}_{b}^{D B B}, \pi_{\beta b}, \pi_{\alpha b}, \pi_{\beta a}\right)=V_{b}^{D B N}\left(\tilde{g}_{a}^{D B B}, \tilde{g}_{b}^{D B N}, \pi_{\alpha b}\right),
\end{aligned}
$$

for $\pi_{\beta a}$ and $\pi_{\beta b}$, we get the equilibrium profits shown in Table 3. The reservation utility of the policy maker in region $a$, i.e. the r.h.s. of eq. (52), is defined by assuming that firm $\beta$ does not lobby region $a\left(g_{a}=\tilde{g}_{a}^{D B N}\right)$ while lobbying region $b\left(g_{b}=\tilde{g}_{b}^{D B B}\right)$. By the same token, the reservation utility of the policy maker in region $b$, i.e. the r.h.s. of eq. (53), is defined by assuming that firm $\beta$ does not lobby region $b\left(g_{b}=\tilde{g}_{b}^{D B N}\right)$ while lobbying region $a\left(g_{a}=\tilde{g}_{a}^{D B B}\right)$. The same kind of logic is used below when solving the games $B I, B O$ and $B N$, in which one of the firms is lobbying both policy makers. Finally, equilibrium contributions of the game $B B$, shown in Table 4 , are obtained from substitution of optimal public good supplies and profits into the contribution functions, i.e. from $\tilde{s}_{\beta a}^{D B B}=f^{2} \tilde{g}^{D B B}-\tilde{\pi}_{\beta a}^{D B B}$ and $\tilde{s}_{\beta b}^{D B B}=h^{2} \tilde{g}^{D B B}-\tilde{\pi}_{\beta b}^{D B B}$.

One firm lobbying both regions and one lobbying the home region only $(B I)$

Suppose that firm $\alpha$ chooses $B$ and firm $\beta$ chooses $I$. Policy makers maximize:

$$
\begin{aligned}
& V_{a}^{D B I}=\mu\left(W_{a}-S_{\alpha b}\right)+(1-\mu) S_{\alpha a}, \\
& V_{b}^{D B I}=\mu\left(W_{b}+S_{\alpha b}\right)+(1-\mu)\left(S_{\alpha b}+S_{\beta b}\right),
\end{aligned}
$$

from which:

$$
\begin{aligned}
& \tilde{g}_{a}^{D B I}=\hat{g}^{D}+2 m h^{2}, \\
& \tilde{g}_{b}^{D B I}=\hat{g}^{D}+2 f^{2}+2 m\left(h^{2}+f^{2}\right) .
\end{aligned}
$$

Assume now that firm $\alpha$ does not lobby. Policy makers maximize:

$$
\begin{aligned}
V_{a}^{D N I} & =\mu W_{a}, \\
V_{b}^{D N I} & =\mu W_{b}+(1-\mu) S_{\beta b},
\end{aligned}
$$

and optimal public goods supplies are:

$$
\begin{aligned}
& \tilde{g}_{a}^{D N I}=\hat{g}^{D}, \\
& \tilde{g}_{b}^{D N I}=\hat{g}^{D}+2 m h^{2} .
\end{aligned}
$$

Solving

$$
\begin{aligned}
& V_{a}^{D B I}\left(\tilde{g}_{a}^{D B I}, \tilde{g}_{b}^{D B I}, \pi_{\alpha a}, \pi_{\alpha b}\right)=V_{a}^{D N I}\left(\tilde{g}_{a}^{D N I}, \tilde{g}_{b}^{D B I}\right), \\
& V_{b}^{D B I}\left(\tilde{g}_{a}^{D B I}, \tilde{g}_{b}^{D B I}, \pi_{\beta b}, \pi_{\alpha b}\right)=V_{b}^{D N I}\left(\tilde{g}_{a}^{D B I}, \tilde{g}_{b}^{D N I}, \pi_{\beta b}\right),
\end{aligned}
$$

for $\pi_{\alpha a}$ and $\pi_{\alpha b}$ we get the equilibrium profits that a firm lobbying both regions makes at home and abroad when the other firm is lobbying only at home (see Table 3). To compute the equilibrium profits of firm $\beta$, assume now that $\alpha$ chooses $B$ while $\beta$ chooses $N$. Policy makers maximize (48) and (49) and the solutions are (50) and (51). Solving the equation

$$
V_{b}^{D B I}\left(\tilde{g}_{a}^{D B I}, \tilde{g}_{b}^{D B I}, \pi_{\beta b}, \pi_{\alpha b}\right)=V_{b}^{D B N}\left(\tilde{g}_{a}^{D B N}, \tilde{g}_{b}^{D B N}, \pi_{\alpha b}\right),
$$

for $\pi_{\beta b}$ we get the equilibrium profits that a firm makes at home when lobbying only at home while the other firm is lobbying both regions (see Table 3). Finally, equilibrium contributions for the game $B I$ (see Table 4) are computed by substitutions of net profits and public good supplies into the compensating contribution schedules. 


\section{One firm lobbying both regions and the other lobbying abroad $(B O)$}

Suppose that firm $\alpha$ chooses $B$ and firm $\beta$ chooses $O$. Policy makers maximize:

$$
\begin{aligned}
& V_{a}^{D B O}=\mu\left(W_{a}-S_{\alpha b}+S_{\beta a}\right)+(1-\mu)\left(S_{\alpha a}+S_{\beta a}\right), \\
& V_{b}^{D B O}=\mu\left(W_{b}-S_{\beta a}+S_{\alpha b}\right)+(1-\mu) S_{\alpha b},
\end{aligned}
$$

from which:

$$
\begin{aligned}
& \tilde{g}_{a}^{D B O}=\hat{g}^{D}+2 f^{2}+2 m\left(h^{2}+f^{2}\right), \\
& \tilde{g}_{b}^{D B O}=\hat{g}^{D}+2(1+m) f^{2} .
\end{aligned}
$$

Assume now that firm $\beta$ does not lobby. Hence the game is $B N$, policy makers maximize (48) and (49), and the solutions are (50) and (51). Solving the equation

$$
V_{a}^{D B O}\left(\tilde{g}_{a}^{D B O}, \tilde{g}_{b}^{D B O}, \pi_{\alpha a}, \pi_{\beta a}, \pi_{\alpha b}\right)=V_{a}^{D B N}\left(\tilde{g}_{a}^{D B N}, \tilde{g}_{b}^{D B N}, \pi_{\alpha a}, \pi_{\alpha b}\right),
$$

for $\pi_{\beta a}$ we get the equilibrium profits that a firm makes abroad when lobbying only abroad while the other firm is lobbying both regions (see Table 3). Assume now that firm $\alpha$ does not lobby. Policy makers maximize:

$$
\begin{aligned}
& V_{a}^{D N O}=\mu\left(W_{a}+S_{\beta a}\right)+(1-\mu) S_{\beta a}, \\
& V_{b}^{D N O}=\mu\left(W_{b}-S_{\beta a}\right)
\end{aligned}
$$

from which:

$$
\begin{aligned}
& \tilde{g}_{a}^{D N O}=\hat{g}^{D}+2(1+m) f^{2}, \\
& \tilde{g}_{b}^{D N O}=\hat{g}^{D} .
\end{aligned}
$$

Solving

$$
\begin{aligned}
& V_{a}^{D B O}\left(\tilde{g}_{a}^{D B O}, \tilde{g}_{b}^{D B O}, \pi_{\alpha a}, \pi_{\beta a}, \pi_{\alpha b}\right)=V_{a}^{D N O}\left(\tilde{g}_{a}^{D N O}, \tilde{g}_{b}^{D B O}, \pi_{\beta a}\right), \\
& V_{b}^{D B O}\left(\tilde{g}_{a}^{D B O}, \tilde{g}_{b}^{D B O}, \pi_{\beta a}, \pi_{\alpha b}\right)=V_{b}^{D N O}\left(\tilde{g}_{a}^{D B O}, \tilde{g}_{b}^{D N O}, \pi_{\beta a}\right),
\end{aligned}
$$

for $\pi_{\alpha a}$ and $\pi_{\alpha b}$ we get the equilibrium profits that a firm lobbying both regions makes at home and abroad when the other firm is lobbying only abroad (see Table 3). Finally, equilibrium contributions for the game $B O$ (see Table 4) are computed by substitutions of net profits and public good supplies into the compensating contribution schedules.

\section{One firm lobbying both regions and the other no lobbying $(B N)$}

Suppose that firm $\alpha$ chooses $B$ and $\beta$ chooses $N$. Policy makers maximize (48) and (49) and the solutions are (50) and (51). Assume now that firm $\alpha$ is not lobbying. Policy makers maximize $V_{a}^{D N N}=\mu W_{a}$ and $V_{b}^{D N N}=\mu W_{b}$. The solution is the no-lobbying optimal public good supply $\hat{g}^{D}$ for both $g_{a}$ and $g_{b}$. Solving

$$
\begin{aligned}
& V_{a}^{D B N}\left(\tilde{g}_{a}^{D B N}, \tilde{g}_{b}^{D B N}, \pi_{\alpha a}, \pi_{\alpha b}\right)=V_{a}^{D N N}\left(\hat{g}_{a}^{D}, \hat{g}_{b}^{D B N}\right) \\
& V_{b}^{D B N}\left(\tilde{g}_{a}^{D B N}, \tilde{g}_{b}^{D B N}, \pi_{\alpha b}\right)=V_{b}^{D N N}\left(\hat{g}_{a}^{D B N}, \hat{g}_{b}^{D}\right)
\end{aligned}
$$

for $\pi_{\alpha a}$ and $\pi_{\alpha b}$ we get the equilibrium profits that a firm lobbying both regions makes at home and abroad when the other firm is not lobbying (see Table 3). Profits at home and abroad of the no-lobbying firm $\beta$ are computed by substituting the optimal public good supplies into the corresponding profit functions. Finally, equilibrium contributions for the game $B N$ (see Table 4) are computed by simple substitutions of net profits and public good supplies into the compensating contribution schedules of firm $\alpha$. 


\section{Both firms lobbying only the home region $(I I)$}

When both firms lobby only the home region, the policy makers' objective functions are (26) and (27) in the text. By maximizing (26) with respect to $g_{a}$ and (27) with respect to $g_{b}$, we get the optimal public good supplies $\tilde{g}^{D I I}$ in (28). To compute the equilibrium profits, assume that $\beta$ lobbies at home $(I)$, while $\alpha$ does not lobby $(N)$. Policy makers maximize (58) and (59), and the solutions are (60) and (61). Solving the equation

$$
V_{a}^{D I I}\left(\tilde{g}_{a}^{D I I}, \tilde{g}_{b}^{D I I}, \pi_{\alpha a}\right)=V_{a}^{D N I}\left(\tilde{g}_{a}^{D N I}, \tilde{g}_{b}^{D N I}\right)
$$

for the home profits $\pi_{\alpha a}$, and then adding the "abroad" profits, $f^{2} \tilde{g}^{D I I}$, we get total profits $\tilde{\pi}^{D I I}$ in (29). Equilibrium contributions, shown in Table 4, are obtained by substituting (home) net profits and public good supply into firm $\alpha$ 's compensating contribution schedule to region $a$.

\section{One firm lobbying the home region and the other lobbying abroad $(I O)$}

Suppose that firm $\alpha$ chooses $I$ and firm $\beta$ chooses $O$. Policy makers maximize:

$$
\begin{aligned}
& V_{a}^{D I O}=\mu\left(W_{a}+S_{\beta a}\right)+(1-\mu)\left(S_{\alpha a}+S_{\beta a}\right), \\
& V_{b}^{D I O}=\mu\left(W_{b}-S_{\beta a}\right),
\end{aligned}
$$

and the solutions are:

$$
\begin{aligned}
& \tilde{g}_{a}^{D I O}=\hat{g}^{D}+2 f^{2}+2 m\left(h^{2}+f^{2}\right), \\
& \tilde{g}_{b}^{D I O}=\hat{g}^{D} .
\end{aligned}
$$

Assume now that firm $\alpha$ does not lobby while firm $\beta$ lobbies at home, so that the game is $N O$. Policy makers maximize (66) and (67), and the solutions are (68) and (69). Solving the equation

$$
V_{a}^{D I O}\left(\tilde{g}_{a}^{D I O}, \tilde{g}_{b}^{D I O}, \pi_{\alpha a}, \pi_{\beta a}\right)=V_{a}^{D N O}\left(\tilde{g}_{a}^{D N O}, \tilde{g}_{b}^{D N O}, \pi_{\beta a}\right)
$$

for $\pi_{\alpha a}$ we obtain the equilibrium profits that a firm makes at home when lobbying at home only while the other firm is lobbying away only. Next we assume that firm $\alpha$ lobbies at home while firm $\beta$ does not lobby. Policy makers maximize:

$$
\begin{aligned}
V_{a}^{D I N} & =\mu W_{a}+(1-\mu) S_{\alpha a}, \\
V_{b}^{D I N} & =\mu W_{b},
\end{aligned}
$$

and optimal public goods supplies are:

$$
\begin{aligned}
& \tilde{g}_{a}^{D I N}=\hat{g}^{D}+2 m h^{2}, \\
& \tilde{g}_{b}^{D I N}=\hat{g}^{D} .
\end{aligned}
$$

Solving the equation

$$
V_{b}^{D I O}\left(\tilde{g}_{a}^{D I O}, \tilde{g}_{b}^{D I O}, \pi_{\beta a}\right)=V_{b}^{D I N}\left(\tilde{g}_{a}^{D I N}, \tilde{g}_{b}^{D I N}\right)
$$

for $\pi_{\beta a}$ we obtain the profits that a firm make abroad when lobbying only abroad whereas the other firm is lobbying only at home. Equilibrium contributions for the game $I O$ (see Table 4) are computed by substituting net profits and public good supplies into the corresponding contribution schedules.

\section{One firm lobbying the home region and the other no lobbying $(I N)$}

Suppose that firm $\beta$ chooses $I$ and firm $\alpha$ chooses $N$. Policy makers maximize (58) and (59) and the solutions are (60) and (61). Assuming that firm $\beta$ is not lobbying, policy makers maximize 
$V_{a}^{D N N}=\mu W_{a}$ and $V_{b}^{D N N}=\mu W_{b}$. The solution is the no-lobbying optimal public good supply $\hat{g}^{D}$ for both $g_{a}$ and $g_{b}$. Solving

$$
V_{b}^{D I N}\left(\tilde{g}_{a}^{D N I}, \tilde{g}_{b}^{D N I}, \pi_{\beta b}\right)=V_{b}^{D N N}\left(\hat{g}_{a}^{D}, \hat{g}_{b}^{D}\right)
$$

for $\pi_{\beta b}$ we get the equilibrium profits that a firm makes at home when lobbying only at home while the other firm is not lobbying (see Table 3). Firm $\beta$ 's profits abroad, and profits at home and abroad of the no-lobbying firm $\alpha$ are computed by substituting the optimal public good supplies into the corresponding profit functions. Equilibrium contributions for the game $I N$ (see Table 4) are computed by substituting net profits and public good supplies into firm $\beta$ 's compensating contribution schedule.

\section{Both firms lobbying only abroad $(O O)$}

When both firms lobby only abroad, the policy makers' objective functions are (30) and (31) in the text. By maximizing (30) with respect to $g_{a}$ and (31) with respect to $g_{b}$, we get the optimal public good supplies $\tilde{g}^{D O O}$ in (32). Assume now that firm $\alpha$ does not lobby while firm $\beta$ lobbies abroad. The game is $N O$, policy makers maximize (66) and (67), and the solutions are (68) and (69). Solving the equation

$$
V_{b}^{D O O}\left(\tilde{g}_{a}^{D O O}, \tilde{g}_{b}^{D O O}, \pi_{\alpha b}, \pi_{\beta a}\right)=V_{b}^{D N O}\left(\tilde{g}_{a}^{D N O}, \tilde{g}_{b}^{D N O}, \pi_{\beta a}\right)
$$

for $\pi_{\alpha b}$ we obtain the equilibrium profits that a firm makes abroad when both firms are lobbying abroad only (see Table 3). Adding the home profits, we get total profits $\tilde{\pi}^{D O O}$ shown in (33). Equilibrium contributions, shown in Table 4, are computed by substituting (abroad) net profits and public good supply into firm $\alpha$ 's compensating contribution schedule to region $b$.

\section{One firm lobbying abroad and the other no lobbying $(O N)$}

Suppose that firm $\beta$ chooses $O$ and firm $\alpha$ chooses $N$. Policy makers maximize (66) and (67) and the solutions are (68) and (69). Assuming that firm $\beta$ is not lobbying, policy makers maximize $V_{a}^{D N N}=\mu W_{a}$ and $V_{b}^{D N N}=\mu W_{b}$. The solution is the no-lobbying optimal public good supply $\hat{g}^{D}$ for both $g_{a}$ and $g_{b}$. Solving

$$
V_{a}^{D N O}\left(\tilde{g}_{a}^{D N O}, \tilde{g}_{b}^{D N O}, \pi_{\beta a}\right)=V_{a}^{D N N}\left(\hat{g}_{a}^{D}, \hat{g}_{b}^{D}\right)
$$

for $\pi_{\beta a}$ we obtain the equilibrium profits that a firm earns abroad when lobbying only abroad while the other firm is no lobbying (see Table 3). Firm $\beta$ 's profits at home, and profits at home and abroad of the no-lobbying firm $\alpha$ are computed by substituting the optimal public good supplies into the corresponding profit functions. Equilibrium contributions for the game $O N$ (see Table 4) are computed by substituting net profits and public good supply into firm $\beta$ 's contribution schedule.

\section{A.3 Proof of Proposition 2}

From the where-to-lobby game in Table 1 , one can see that for $\mu \neq 1$ strategy $N$ is strictly dominated by strategy $I$, since $\Delta \pi^{I j}-\Delta \pi^{N j}=m h^{4}>0$ for all $j \in\{B, I, O, N\}$. Hence both firms never play strategy $N$. Since $\Delta \pi^{B i}-\Delta \pi^{I i}=\left(m-m^{-1}\right) f^{4}, \Delta \pi^{B i}-\Delta \pi^{O i}=m h^{4}-\left(1+m^{-1}\right) f^{4}$ and $\Delta \pi^{I i}-\Delta \pi^{O i}=m h^{4}-(1+m) f^{4}$ for all $i \in\{B, I, O\}$, all the Nash equilibria of the game are in dominant strategies. Next, it is $\Delta \pi^{B i}=\Delta \pi^{I i}$ iff $\mu=\frac{1}{2}, \Delta \pi^{B i}=\Delta \pi^{O i}$ iff $\mu=\mu^{B O}(\delta ; c)$ defined in (34), and $\Delta \pi^{I i}=\Delta \pi^{O i}$ iff $\mu=\mu^{I O}(\delta ; c)$ defined in (35). Plain algebra shows that both $\mu^{B O}(\delta ; c)$ and $\mu^{I O}(\delta ; c)$ are monotonically increasing in $\delta$, that $\mu^{B O}(1 ; c)=(3-\sqrt{5}) / 2 \approx .38$, $\mu^{B O}\left(\delta_{\max } ; c\right)=1, \mu^{I O}(1 ; c)=0, \mu^{I O}\left(\delta_{\max } ; c\right)=1$, and that the three curves $\mu=\frac{1}{2}, \mu=\mu^{B O}(\delta ; c)$ and $\mu=\mu^{I O}(\delta ; c)$ have a unique intersection at $\delta=\tilde{\delta}(c)$ defined in (36). These properties imply that if $\Delta \pi^{B i}-\Delta \pi^{I i} \geq 0$ (i.e. $\mu \leq \frac{1}{2}$ ) and $\Delta \pi^{B i}-\Delta \pi^{O i} \geq 0$ (i.e. $\mu \leq \mu^{B O}$ ), then $B$ is the dominant strategy for each player. Thus $B B$ is the unique Nash equilibrium of the "where-to-lobby" game. 
If $\Delta \pi^{B i}-\Delta \pi^{I i}<0$ (i.e. $\mu>\frac{1}{2}$ ) and $\Delta \pi^{I i}-\Delta \pi^{O i} \geq 0$ (i.e. $\mu \leq \mu^{I O}$ ) the unique Nash equilibrium in dominant strategies is $I I$. Finally, if $\Delta \pi^{B i}-\Delta \pi^{O i}<0$ (i.e. $\mu>\mu^{B O}$ ) and $\Delta \pi^{I i}-\Delta \pi^{O i}<0$ (i.e. $\mu>\mu^{I O}$ ) the Nash equilibrium is $O O$.

\section{A.4 Proof of Corollary 1}

From Table 1 it is $\Delta \pi^{B B}-\Delta \pi^{I I}=2(1+m) h^{2} f^{2}+\left(m-m^{-1}\right) f^{4}$ and $\Delta \pi^{B B}-\Delta \pi^{O O}=m h^{4}+$ $2 m h^{2} f^{2}-\left(1+m^{-1}\right) f^{4}$. For $\mu<\frac{1}{2}, \Delta \pi^{B B}>\Delta \pi^{I I}$, since $m>m^{-1}$, and $\Delta \pi^{B B}>\Delta \pi^{O O}$, since $2 m>1+m^{-1}$ and $h \geq f$, implying that when the strategy pair $B B$ is a Nash equilibrium it is also Pareto efficient. For $\mu \geq \frac{1}{2}$, we need to compare the equilibria $I I$ and $O O$. From $\Delta \pi^{I I}-\Delta \pi^{O O} \geq 0$ it is $\mu \leq \mu^{E}(\delta ; c) \equiv \frac{h^{4}-f^{4}}{h^{4}+2 h^{2} f^{2}}$, where $\mu^{E}(\delta ; c)$ is monotonically increasing in $\delta$, with $\mu^{E}(1 ; c)=0$, $\mu^{E}\left(\delta_{\max } ; c\right)=1$, and such that, see eq. $(35), \mu^{E}(\delta ; c)<\mu^{I O}(\delta ; c)$ for all $\delta \in\left[1, \delta_{\max }\right]$. Hence, since $\mu^{I O}(\delta ; c)$ defines the boundary between the Nash equilibria $I I$ and $O O$, the strategy pair $I I$ is Pareto efficient if and only if $\mu \leq \mu^{E}(\delta ; c)$, provided that $\mu^{E} \geq \frac{1}{2}$.

\section{A.5 Proof of Proposition 3}

As for the comparison of net profits, using (20), (25), (29) and (33) it is $\tilde{\pi}^{C}-\tilde{\pi}^{D B B}=\left(2+m^{-1}\right) f^{4} \geq$ $0, \tilde{\pi}^{C}-\tilde{\pi}^{D I I}=2(1+m) h^{2} f^{2}+(2+m) f^{4} \geq 0$ and $\tilde{\pi}^{C}-\tilde{\pi}^{D O O}=m h^{4}+2 m h^{2} f^{2}+f^{4}>0$, which shows that profits are higher under centralization. As for contributions, from (21) and Table 4, it is $\tilde{s}_{\alpha a}^{D B B}+\tilde{s}_{\alpha b}^{D B B}-\tilde{s}^{C}=\left(2+m^{-1}\right) f^{4} \geq 0, \tilde{s}^{C}-\tilde{s}_{\alpha a}^{D I I}=m f^{4} \geq 0$ and $\tilde{s}^{C}-\tilde{s}_{\alpha b}^{D O O}=m h^{4}-f^{4}$. From the latter one obtains that $\tilde{s}^{C} \geq \tilde{s}_{\alpha b}^{D O O}$ iff $\mu \leq \mu^{S}(\delta ; c) \equiv \frac{h^{4}}{h^{4}+f^{4}} \cdot \mu^{S}(\delta ; c)$ is monotonically increasing in $\delta$, with $\mu^{S}(1 ; c)=\frac{1}{2}, \mu^{S}\left(\delta_{\max } ; c\right)=1$, and that $\mu^{S}(\delta ; c)>\mu^{I O}(\delta ; c)$, meaning that the region in which $O O$ is a Nash equilibrium is divided into two areas: $\tilde{s}^{C}<\tilde{s}_{\alpha b}^{D O O}$, for $\mu>\mu^{S}$; $\tilde{s}^{C} \geq \tilde{s}_{\alpha b}^{D O O}$, otherwise. As for public good provision and social welfare, from (18) and (24) it is $\hat{g}^{C}=\tilde{g}^{D B B}$, which implies that aggregate social welfare is the same under centralization and under the equilibria $B B$. By the comparison of (18) and (28) it follows that $\tilde{g}^{D I I} \leq \hat{g}^{C}$; aggregate social welfare is larger in the decentralized equilibrium $I I$ since $\left|\tilde{g}^{D I I}-\hat{g}^{C}\right| \leq\left|\tilde{g}^{C}-\hat{g}^{C}\right|$, given that $\hat{g}^{C}$ maximizes social welfare, which is quadratic in public goods supply. Finally, using (18) and (32) one can see that $\tilde{g}^{D O O}<\hat{g}^{C}$; aggregate social welfare is larger in the decentralized equilibrium $O O$ since $0 \leq \tilde{g}^{D O O}-\hat{g}^{C} \leq \tilde{g}^{C}-\hat{g}^{C}$.

\section{B Appendix: Lobbying for the market}

\section{B.1 Proof of Lemma 1}

We first derive the optimal public goods levels by maximizing $W^{J_{a} K_{b}}=W_{a}^{J_{a} K_{b}}+W_{b}^{J_{a} K_{b}}, J, K=$ $\{H, F\}$, as defined in (38)-(41), with respect to $g_{a}$ and $g_{b}$. This gives

$$
\hat{g}_{a}^{H_{a} H_{b}}=\hat{g}_{b}^{H_{a} H_{b}}=\hat{g}_{a}^{H_{a} F_{b}}=\hat{g}_{b}^{F_{a} H_{b}}=3 H^{2}, \hat{g}_{a}^{F_{a} F_{b}}=\hat{g}_{b}^{F_{a} F_{b}}=\hat{g}_{b}^{H_{a} F_{b}}=\hat{g}_{a}^{F_{a} H_{b}}=3 F^{2} .
$$

Monopoly profits when supplying the home and the foreign region are $3 H^{4}$ and $3 F^{4}$, respectively. Thus, given $S_{\rho}^{H}$ and $S_{\rho}^{F}$, with $0 \leq S_{\rho}^{H} \leq 3 H^{4}$ and $0 \leq S_{\rho}^{F} \leq 3 F^{4}$, the politician's value functions in the four possible cases are

$$
\begin{aligned}
V^{H_{a} H_{b}} & =\mu \frac{9 H^{4}}{2}+(1-\mu)\left(S_{\alpha}^{H}+S_{\beta}^{H}\right)+2 \mu \bar{y} \\
V^{H_{a} F_{b}} & =\mu \frac{9\left(H^{4}+F^{4}\right)}{4}+(1-\mu)\left(S_{\alpha}^{H}+S_{\alpha}^{F}\right)+2 \mu \bar{y} \\
V^{F_{a} H_{b}} & =\mu \frac{9\left(H^{4}+F^{4}\right)}{4}+(1-\mu)\left(S_{\beta}^{H}+S_{\beta}^{F}\right)+2 \mu \bar{y} \\
V^{F_{a} F_{b}} & =\mu \frac{9 F^{4}}{2}+(1-\mu)\left(S_{\alpha}^{F}+S_{\beta}^{F}\right)+2 \mu \bar{y} .
\end{aligned}
$$




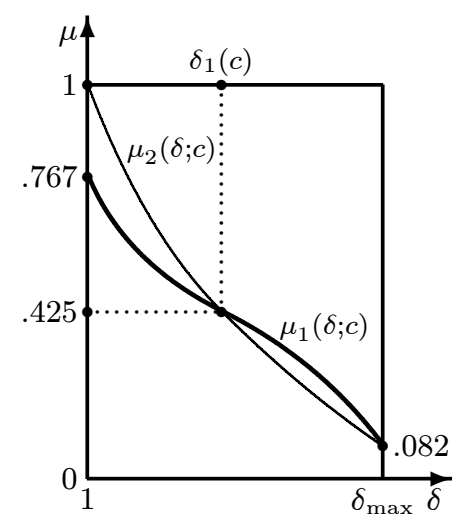

Figure 3: An illustration of Proposition 4

Consider firm $\alpha$ (the same argument holds true for firm $\beta$ ). Given $S_{\beta}^{H}$ and $S_{\beta}^{F}$ the government chooses $H_{a} H_{b}$ iff $V^{H_{a} H_{b}} \geq V^{H_{a} F_{b}}, V^{H_{a} H_{b}} \geq V^{F_{a} H_{b}}, V^{H_{a} H_{b}} \geq V^{F_{a} F_{b}}$; after some algebra these inequalities reduce to $S_{\alpha}^{H} \geq T^{H}\left(S_{\beta}^{F}\right)$ and $S_{\alpha}^{F} \leq T^{F}\left(S_{\beta}^{H}\right)$, where

$$
\begin{aligned}
& T^{H}\left(S_{\beta}^{F}\right)=\max \left\{-\frac{9 \mu\left(H^{4}-F^{4}\right)}{4(1-\mu)}+S_{\beta}^{F}, 0\right\}, \\
& T^{F}\left(S_{\beta}^{H}\right)=\min \left\{\frac{9 \mu\left(H^{4}-F^{4}\right)}{4(1-\mu)}+S_{\beta}^{H}, 3 F^{4}\right\} .
\end{aligned}
$$

Analogously one gets that the government chooses $F_{a} F_{b}$ iff $S_{\alpha}^{H} \leq T^{H}\left(S_{\beta}^{F}\right)$ and $S_{\alpha}^{F} \geq T^{F}\left(S_{\beta}^{H}\right)$, $H_{a} F_{b}$ iff $S_{\alpha}^{H}>T^{H}\left(S_{\beta}^{F}\right)$ and $S_{\alpha}^{F}>T^{F}\left(S_{\beta}^{H}\right)$, and $F_{a} H_{b}$ iff $S_{\alpha}^{H}<T^{H}\left(S_{\beta}^{F}\right)$ and $S_{\alpha}^{F}<T^{F}\left(S_{\beta}^{H}\right)$. The profit function of the firm is then defined as

$$
\Pi_{\alpha}\left(S_{\alpha}^{H}, S_{\alpha}^{F} ; S_{\beta}^{H}, S_{\beta}^{F}\right)= \begin{cases}3 H^{4}-S_{\alpha}^{H} & \text { if } S_{\alpha}^{H} \geq T^{H}\left(S_{\beta}^{F}\right) \text { and } S_{\alpha}^{F} \leq T^{F}\left(S_{\beta}^{H}\right), \\ 3 F^{4}-S_{\alpha}^{F} & \text { if } S_{\alpha}^{H} \leq T^{H}\left(S_{\beta}^{F}\right) \text { and } S_{\alpha}^{F} \geq T^{F}\left(S_{\beta}^{H}\right), \\ 3\left(H^{4}+F^{4}\right)-S_{\alpha}^{H}-S_{\alpha}^{F} & \text { if } S_{\alpha}^{H}>T^{H}\left(S_{\beta}^{F}\right) \text { and } S_{\alpha}^{F}>T^{F}\left(S_{\beta}^{H}\right), \\ 0 & \text { if } S_{\alpha}^{H}<T^{H}\left(S_{\beta}^{F}\right) \text { and } S_{\alpha}^{F}<T^{F}\left(S_{\beta}^{H}\right) .\end{cases}
$$

Profit maximization requires the firm to set $S_{\alpha}^{H}=T^{H}\left(S_{\beta}^{F}\right)+\varepsilon$ and $S_{\alpha}^{F}=T^{F}\left(S_{\beta}^{H}\right)+\varepsilon$, with $\varepsilon>0$ as close as possible to zero. Since the same profit maximizing behavior holds true for firm $\beta$, the two firms will engage in a Bertrand-type competition in contributions, leading to the unique Nash equilibrium (pure) strategy profile: $\hat{S}_{\rho}^{F}=3 F^{4}$ and $\hat{S}_{\rho}^{H}=\max \left\{\hat{T}^{H}, 0\right\}$, with $\hat{T}^{H}=T^{H}\left(\hat{S}_{\rho}^{F}\right)$ as defined in (43).

\section{B.2 Proof of Proposition 4}

From $\hat{T}^{H}=0$, with $\hat{T}^{H}$ defined in (43), we get

$$
\mu_{2}(\delta ; c)=\frac{4 F^{4}}{F^{4}+3 H^{4}},
$$

where $H$ and $F$ are defined in (37). Eq. (78) divides the closed set $S=(\mu, \delta) \in[0,1] \times\left[1, \delta_{\max }\right]$ in two regions (see Figure 3): $\hat{S}^{H}>0$ for $\mu<\mu_{2}$, and $\hat{S}^{H}=0$ otherwise. $\mu_{2}(\delta ; c) \in C^{2}$ is monotonically decreasing in $\delta$, with $\mu_{2}(1 ; c)=1$ and $\mu_{2}\left(\delta_{\max } ; c\right)=\frac{4}{49}=.082$.

From

$$
\hat{V}^{h f}-\mu \frac{9 H^{4}}{2}-2(1-\mu) \hat{T}^{H}-2 \mu \bar{y}=0
$$


we derive

$$
\mu_{1}(\delta ; c)=\frac{12 F^{4}}{3 F^{4}+\left[(h+f)^{2}+2\left(h^{2}+f^{2}\right)\right]^{2}},
$$

where $h$ and $f$ are defined in (5). One can see that $\mu_{1}(\delta ; c) \in C^{2}, \mu_{1}(1 ; c)=\frac{972}{1267} \cong .767$, $\mu_{1}\left(\delta_{\max } ; c\right)=\frac{4}{49}$, and that $\mu_{1}(\delta ; c)$ and $\mu_{2}(\delta ; c)$ have a unique intersection at $\delta=\delta_{1}(c) \equiv \frac{5+17 c}{22 c}$ for $\delta \in\left[1, \delta_{\max }\right)$, for which $\mu=\frac{334084}{786289} \cong .425$. Thus, for $\delta \in\left[1, \delta_{1}\right]$, the locus defined by eq. (79) separates the subset of $S$ in which $\hat{S}^{H}>0$ into two subsets such that: $\hat{V}^{h f}>\hat{V}^{H}$ for $\mu>\mu_{1}$ and $\hat{V}^{h f} \leq \hat{V}^{H}$ otherwise, proving the first part of the proposition. For $\delta \in\left(\delta_{1}, \delta_{\max }\right)$, if $\mu \leq \mu_{1}$ then $\hat{V}^{h f}<\hat{V}^{H}$ since $\mu_{1}>\mu_{2}$. If $\mu>\mu_{2}$ then $\hat{S}^{H}=0$. Define $\Psi(\mu, \delta ; c)=\hat{V}^{h f}-\mu \frac{9 H^{4}}{4}, \Psi \in C^{2}$. Since $\Psi(\mu, 1 ; c)>0, \Psi\left(\mu, \delta_{\max } ; c\right)=0$ and there is a unique root at $\delta=\delta_{1}$ for $\delta \in\left[1, \delta_{\max }\right)$, then $\Psi<0$ for all $\delta \in\left(\delta_{1}, \delta_{\max }\right)$, proving that only the home firm enters the market without paying any contribution.

\section{B.3 Proof of Lemma 2}

The proof is conducted in three steps. The first step proves the first part of the lemma and derives the politicians' value functions when one firm only is allowed into each regional market. The second and third steps derive the politicians' value functions in the remaining cases.

Step 1. Both regional governments admit one firm only. By deriving the optimal public goods levels through the maximization in $g_{a}$ and $g_{b}$, respectively, of $W_{a}^{J_{a} K_{b}}$ and $W_{b}^{J_{a} K_{b}}, J, K=\{H, F\}$, as defined in (38)-(41), and given $S_{\rho}^{H}$ and $S_{\rho}^{F}, \rho=\{\alpha, \beta\}$, with $0 \leq S_{\rho}^{H} \leq 3 H^{4}$ and $0 \leq S_{\rho}^{F} \leq 3 F^{4}$, we obtain region $a$ politician's value functions in the four possible cases

$$
\begin{aligned}
V_{a}^{H_{a} H_{b}} & =\mu \frac{9 H^{4}}{4}+(1-\mu) S_{\alpha}^{H}+\mu \bar{y} \\
V_{a}^{H_{a} F_{b}} & =\mu\left(\frac{9 H^{4}}{4}+F^{4}\right)-\mu S_{\alpha}^{F}+(1-\mu) S_{\alpha}^{H}+\mu \bar{y} \\
V_{a}^{F_{a} H_{b}} & =\mu \frac{F^{4}}{4}+S_{\beta}^{F}+\mu \bar{y} \\
V_{a}^{F_{a} F_{b}} & =\mu \frac{5 F^{4}}{4}-\mu S_{\alpha}^{F}+S_{\beta}^{F}+\mu \bar{y} .
\end{aligned}
$$

Given $S_{\beta}^{F}$, it is a (weakly) dominant strategy for region $a$ (and symmetrically the same holds true for region $b$ ) to choose the home firm iff $V_{a}^{H_{a} H_{b}} \geq V_{a}^{F_{a} H_{b}}$ and $V_{a}^{H_{a} F_{b}} \geq V_{a}^{F_{a} F_{b}}$. These two inequalities are satisfied for the same condition, i.e.

$$
S_{\alpha}^{H}\left(S_{\beta}^{F}\right) \geq \max \left\{-\frac{\mu\left(9 H^{4}-F^{4}\right)}{4(1-\mu)}+\frac{S_{\beta}^{F}}{1-\mu}, 0\right\} .
$$

Bertrand competition in contributions implies that $\hat{S}_{\rho}^{F}=F^{4}$ and thus it is

$$
\hat{S}_{\rho}^{H}=\max \left\{-\frac{\mu\left(9 H^{4}-F^{4}\right)}{4(1-\mu)}+\frac{F^{4}}{1-\mu}, 0\right\},
$$

proving equation (45) in the lemma. One needs to check that $\hat{S}_{\rho}^{H} \leq 3 H^{4}$. For $\mu \neq 1$, this requires $\mu(\delta) \leq \mu^{T}(\delta) \equiv 4 \frac{3 H^{4}-F^{4}}{3 H^{4}+F^{4}}$. By recalling (37), it is immediate to show that it is $\mu^{T}(1)=2$ and $\frac{\partial \mu^{T}(\delta)}{\partial \delta}>0$. Hence $\hat{S}_{\rho}^{H}$ is always smaller than the profits realized in the home region.

Thus, when only one firm is allowed to enter a regional market, the home firm wins the contest for the market and the politician's value function (in each region) is $\hat{V}_{a}^{H_{a} H_{b}}$ in Table 2 .

Step 2. Both regional governments allow both firms in their market. This case has been examined in section 3, where policy without lobbying has been described. Using the optimal public good provision given in (13) and substituting it into (10), region $a$ politician's value function when both 
firms are allowed to enter their market is $\hat{V}_{a}^{h f_{a} h f_{b}}$, shown in Table 2.

Step 3. One regional government admits one firm only and the other one admits both. Suppose, without loss of generality, that region $a$ lets both firms in, while region $b$ allows only one of them to enter its regional market. In the case in which firm $\beta$ gets region $b$ 's market, social welfare becomes

$$
\begin{aligned}
W_{a}^{h f_{a} H_{b}} & =\mu \frac{(h+f)^{2} g_{a}+2 h^{2} g_{a}}{2}-\frac{g_{a}^{2}}{4}, \\
W_{b}^{h f_{a} H_{b}} & =\mu \frac{3 H^{2} g_{b}+2 f^{2} g_{a}}{2}-\frac{g_{b}^{2}}{4}+(1-\mu) S_{\beta}^{H} .
\end{aligned}
$$

On the other hand, in the case in which firm $\alpha$ gets region $b$ 's market, the corresponding social welfare functions are

$$
\begin{aligned}
& W_{a}^{h f_{a} F_{b}}=\mu \frac{(h+f)^{2} g_{a}+2 h^{2} g_{a}+2 F^{2} g_{b}-2 S_{\alpha}^{F}}{2}-\frac{g_{a}^{2}}{4}, \\
& W_{b}^{h f_{a} F_{b}}=\mu \frac{F^{2} g_{b}+2 f^{2} g_{a}+2 S_{\alpha}^{F}}{2}-\frac{g_{b}^{2}}{4}+(1-\mu) S_{\alpha}^{F} .
\end{aligned}
$$

By maximizing each regional social welfare function in the local public good supply, one obtains the corresponding politicians' value functions

$$
\begin{aligned}
\hat{V}_{a}^{h f_{a} H_{b}} & =\mu \frac{\left[(h+f)^{2}+2 h^{2}\right]^{2}}{4}, \\
V_{b}^{h f_{a} H_{b}} & =\mu \frac{9 H^{4}+4 f^{2}\left[(h+f)^{2}+2 h^{2}\right]}{4}+(1-\mu) S_{\beta}^{H}, \\
V_{a}^{h f_{a} F_{b}} & =\mu \frac{\left[(h+f)^{2}+2 h^{2}\right]^{2}+4 F^{4}}{4}-\mu S_{\alpha}^{F}, \\
V_{b}^{h f_{a} F_{b}} & =\mu \frac{F^{4}+4 f^{2}\left[(h+f)^{2}+2 h^{2}\right]}{4}+S_{\alpha}^{F} .
\end{aligned}
$$

Region $b$ allows firm $\beta$ in iff $V_{b}^{h f_{a} H_{b}} \geq V_{b}^{h f_{a} F_{b}}$ that requires

$$
S_{\beta}^{H}\left(S_{\alpha}^{F}\right) \geq \max \left\{-\frac{\mu\left(9 H^{4}-F^{4}\right)}{4(1-\mu)}+\frac{S_{\alpha}^{F}}{1-\mu}, 0\right\} .
$$

By Bertrand competition, $\hat{S}_{\alpha}^{F}=F^{4}$ and

$$
\hat{S}_{\beta}^{H}=\max \left\{-\frac{\mu\left(9 H^{4}-F^{4}\right)}{4(1-\mu)}+\frac{F^{4}}{1-\mu}, 0\right\},
$$

where $\hat{S}_{\beta}^{H}>0$ for $\mu<\frac{4 F^{4}}{9 H^{4}-F^{4}}$. Moreover, by the same argument in Step $2, \hat{S}_{\beta}^{H} \leq 3 H^{4}$. Thus, substituting $\hat{S}_{\beta}^{H}$ into $V_{b}^{h f_{a} H_{b}}$ the region $b$ politician's value function is $\hat{V}_{b}^{h f_{a} H_{b}}$ in Table 2 . The same applies symmetrically when region $b$ let both firms in, while region $a$ allows only one of them to enter its regional market.

\section{B.4 Proof of Proposition 6}

Considering the game in Table 2, it is a (weakly) dominant strategy for both regions to admit one firm only iff $\hat{V}_{a}^{h f_{a} H_{b}} \geq \hat{V}_{a}^{h f}$ and $\hat{V}_{a}^{H_{a} H_{b}} \geq \hat{V}_{a}^{h f_{a} H_{b}}$. These inequalities imply (i) $\mu \leq \mu_{6}(\delta ; c) \equiv$ $\frac{4 F^{4}}{\left[(h+f)^{2}+2 h^{2}\right]^{2}}$ for $\mu<\mu_{5}(\delta ; c)$, where $\mu_{5}(\delta ; c)$ is defined in (46), and (ii) $\mu\left\{9 H^{4}-\left[(h+f)^{2}+2 h^{2}\right]^{2}\right\} \geq 0$ for $\mu \geq \mu_{5}(\delta ; c)$. Condition (ii) is always satisfied for all $\delta \in\left[1, \delta_{\max }\right]$ and $c \in(0,1)$; hence one-firm in each region is the unique Nash equilibrium for $\mu \geq \mu_{5}(\delta ; c)$. As for condition (i), it is always satisfied for all $\delta \in\left[1, \delta_{\max }\right]$ and $c \in(0,1)$, since $\mu_{6}(\delta ; c) \geq \mu_{5}(\delta ; c)$. The latter inequality follows by a continuity argument from $\mu_{6}(1 ; c)=\frac{36}{55}>\mu_{5}(1 ; c)=\frac{1}{2}, \mu_{6}\left(\delta_{\max } ; c\right)=\mu_{5}\left(\delta_{\max } ; c\right)=\frac{4}{143}$, and $\mu_{6}(\delta ; c) \neq \mu_{5}(\delta ; c)$ for all $\delta \in\left[1, \delta_{\max }\right)$. Hence one-firm in each region is the unique Nash equilibrium also for $\mu<\mu_{5}(\delta ; c)$. In both cases, by Lemma 2 , it is the home firm to gain access to the market. 


\section{References}

Alesina, A., Angeloni, I. and F. Etro (2003). "International unions." CEPR dp 3913.

Alesina, A., Spolaore, E. and R. Wacziarg (2000). "Economic integration and political disintegration." American Economic Review 90, 1276-97.

Bernheim, B.D. and M.D. Whinston (1986). "Menu actions, resource allocation, and economic influence." Quarterly Journal of Economics 101, 1-31.

Besley, T. and S. Coate (2001). "Lobbying and welfare in a representative democracy." Review of Economic Studies 68, 67-82.

Besley, T. and S. Coate (2002). "Centralized versus decentralized provision of local public goods: A political economy analysis." NBER WP7084.

Bolton, P., Roland, G. and E. Spolaore (1996). "Economic theories of the break-up and integration of nations." European Economic Review 40, 697-705.

Bordignon, M., Manasse, P. and G. Tabellini (2001). "Optimal regional redistribution under asymmetric information." American Economic Review 91, 709-24.

De Melo, J., Panagariya, A. and D. Rodrik (1993). "The new regionalism: a country perspective", in J. de Melo and A. Panagariya (eds) New dimensions in Regional Integration. Cambridge University Press.

Dixit, A., Grossman, G.M. and E. Helpman (1997). "Common agency and coordination: General theory and application to government policy making." Journal of Political Economy 105, 752-769.

Felli, L. and A. Merlo (2001). "Endogenous lobbying." PIER Working Paper 01-055.

Fisman, R. and R. Gatti (2002). "Decentralization and corruption: evidence across countries." Journal of Public Economics, 83, 324-45.

Grossman, G.M. and E. Helpman (2001). Special interest politics. The MIT Press, Cambridge, MA.

Keen, M.J. and C. Kotsogiannis (2002). "Does federalism lead to excessively high taxes?" American Economic Review 92, 363-370.

Lockwood, B. (2002). "Distributive politics and the costs of centralization." Review of Economic Studies $69,313-337$.

Ma, C. (1988). "Unique implementation of incentive contracts with many agents." Review of Economic Studies 55, 555-572.

Mitra, D. (1999). "Endogenous lobbies formation and endogenous protection: a long run model of trade determination." American Economic Review 89, 1116-1134.

Mookherjee, D. (1984). "Optimal incentive schemes with many agents." Review of Economic Studies $51,433-446$.

Oates, W., (1972), Fiscal Federalism. Harcourt-Brace and Jovanovich, New York.

Persson, T. (1998). "Economic policy and special interest politics." Economic Journal 108, 310-327.

Persson, T. and G. Tabellini (2000). Political Economics. MIT Press.

Prud'homme, R. (1994). "On the dangers of Decentralization." World Bank Policy Research WP n.1252.

Redoano, M. (2002). "Does centralization affect the number and size of lobbies?" mimeo.

Wilson, J.D. (1999). "Theories of tax competition." National Tax Journal 52, 269-304. 


\section{CESifo Working Paper Series}

(for full list see www.cesifo.de)

953 Hans Gersbach and Hans Haller, Competitive Markets, Collective Decisions and Group Formation, May 2003

954 Armin Falk, Urs Fischbacher, and Simon Gächter, Living in Two Neighborhoods Social Interactions in the LAB, May 2003

955 Margarita Katsimi, Training, Job Security and Incentive Wages, May 2003

956 Clemens Fuest, Bernd Huber, and Jack Mintz, Capital Mobility and Tax Competition: A Survey, May 2003

957 Edward Castronova, The Price of 'Man' and 'Woman': A Hedonic Pricing Model of Avatar Attributes in a Synthetic World, June 2003

958 Laura Bottazzi and Marco Da Rin, Financing Entrepreneurial Firms in Europe: Facts, Issues, and Research Agenda, June 2003

959 Bruno S. Frey and Matthias Benz, Being Independent is a Great Thing: Subjective Evaluations of Self-Employment and Hierarchy, June 2003

960 Aaron Tornell and Frank Westermann, Credit Market Imperfections in Middle Income Countries, June 2003

961 Hans-Werner Sinn and Wolfgang Ochel, Social Union, Convergence and Migration, June 2003

962 Michael P. Devereux, Measuring Taxes on Income from Capital, June 2003

963 Jakob de Haan, Jan-Egbert Sturm and Bjørn Volkerink, How to Measure the Tax Burden on Labour at the Macro-Level?, June 2003

964 Harry Grubert, The Tax Burden on Cross-Border Investment: Company Strategies and Country Responses, June 2003

965 Kirk A. Collins and James B. Davies, Measuring Effective Tax Rates on Human Capital: Methodology and an Application to Canada, June 2003

966 W. Steven Clark, Using Micro-Data to Assess Average Tax Rates, June 2003

967 Christopher Heady, The 'Taxing Wages' Approach to Measuring the Tax Burden on Labour, June 2003

968 Michael P. Devereux and Alexander Klemm, Measuring Taxes on Income from Capital: Evidence from the UK, June 2003 
969 Bernhard Eckwert and Itzhak Zilcha, The Effect of Better Information on Income Inequality, June 2003

970 Hartmut Egger and Josef Falkinger, The Role of Public Infrastructure for Firm Location and International Outsourcing, June 2003

971 Dag Morten Dalen and Trond E. Olsen, Regulatory Competition and Multi-national Banking, June 2003

972 Matthias Wrede, Tax Deductibility of Commuting Expenses and Residential Land Use with more than one Center, June 2003

973 Alessandro Cigno and Annalisa Luporini, Scholarships or Student Loans? Subsidizing Higher Education in the Presence of Moral Hazard, June 2003

974 Chang Woon Nam, Andrea Gebauer and Rüdiger Parsche, Is the Completion of EU Single Market Hindered by VAT Evasion?, June 2003

975 Michael Braulke and Giacomo Corneo, Capital Taxation May Survive in Open Economies, July 2003

976 Assar Lindbeck, An Essay on Welfare State Dynamics, July 2003

977 Henrik Jordahl and Luca Micheletto, Optimal Utilitarian Taxation and Horizontal Equity, July 2003

978 Martin D. D. Evans and Richard K. Lyons, Are Different-Currency Assets Imperfect Substitutes?, July 2003

979 Thorsten Bayindir-Upmann and Frank Stähler, Market Entry Regulation and International Competition, July 2003

980 Vivek Ghosal, Firm and Establishment Volatility: The Role of Sunk Costs, Profit Uncertainty and Technological Change, July 2003

981 Christopher A. Pissarides, Unemployment in Britain: A European Success Story, July 2003

982 Wolfgang Buchholz, Richard Cornes, and Wolfgang Peters, On the Frequency of Interior Cournot-Nash Equilibria in a Public Good Economy, July 2003

983 Syed M. Ahsan and Panagiotis Tsigaris, Choice of Tax Base Revisited: Cash Flow vs. Prepayment Approaches to Consumption Taxation, July 2003

984 Campbell Leith and Jim Malley, A Sectoral Analysis of Price-Setting Behavior in US Manufacturing Industries, July 2003

985 Hyun Park and Apostolis Philippopoulos, Choosing Club Membership under Tax Competition and Free Riding, July 2003 
986 Federico Etro, Globalization and Political Geography, July 2003

987 Dan Ariely, Axel Ockenfels and Alvin E. Roth, An Experimental Analysis of Ending Rules in Internet Auctions, July 2003

988 Paola Conconi and Carlo Perroni, Self-Enforcing International Agreements and Domestic Policy Credibility, July 2003

989 Charles B. Blankart and Christian Kirchner, The Deadlock of the EU Budget: An Economic Analysis of Ways In and Ways Out, July 2003

990 M. Hasham Pesaran and Allan Timmermann, Small Sample Properties of Forecasts from Autoregressive Models under Structural Breaks, July 2003

991 Hyun Park, Apostolis Philippopoulos and Vangelis Vassilatos, On the Optimal Size of Public Sector under Rent-Seeking competition from State Coffers, July 2003

992 Axel Ockenfels and Alvin E. Roth, Late and Multiple Bidding in Second Price Internet Auctions: Theory and Evidence Concerning Different Rules for Ending an Auction, July 2003

993 Pierre Salmon, The Assignment of Powers in an Open-ended European Union, July 2003

994 Louis N. Christofides and Chen Peng, Contract Duration and Indexation in a Period of Real and Nominal Uncertainty, July 2003

995 M. Hashem Pesaran, Til Schuermann, Björn-Jakob Treutler, and Scott M. Weiner, Macroeconomic Dynamics and Credit Risk: A Global Perspective, July 2003

996 Massimo Bordignon and Sandro Brusco, On Enhanced Cooperation, July 2003

997 David F. Bradford, Addressing the Transfer-Pricing Problem in an Origin-Basis X Tax, July 2003

998 Daniel Gros, Who Needs Foreign Banks?, July 2003

999 Wolfram Merzyn and Heinrich W. Ursprung, Voter Support for Privatizing Education: Evidence on Self-Interest and Ideology, July 2003

1000 Jo Thori Lind, Fractionalization and the Size of Government, July 2003

1001 Daniel Friedman and Donald Wittman, Litigation with Symmetric Bargaining and TwoSided Incomplete Information, July 2003

1002 Matthew Clarke and Sardar M. N. Islam, Health Adjusted GDP (HAGDP) Measures of the Relationship Between Economic Growth, Health Outcomes and Social Welfare, July 2003

1003 Volker Grossmann, Contest for Attention in a Quality-Ladder Model of Endogenous Growth, August 2003 
1004 Marcel Gérard and Joan Martens Weiner, Cross-Border Loss Offset and Formulary Apportionment: How do they affect multijurisdictional firm investment spending and interjurisdictional tax competition ?, August 2003

1005 Burkhard Heer, Nonsuperneutrality of Money in the Sidrauski Model with Heterogeous Agents, August 2003

1006 V. Anton Muscatelli, Piergiovanna Natale, and Patrizio Tirelli, A Simple and Flexible Alternative to the Stability and Growth Pact Deficit Ceilings. Is it at hand?, August 2003

1007 Reto Foellmi and Josef Zweimüller, Inequality and Economic Growth: European Versus U.S. Experiences, August 2003

1008 James S. Costain and Michael Reiter, Business Cycles, Unemployment Insurance, and the Calibration of Matching Models, August 2003

1009 Marco Runkel, Optimal Contest Design when the Designer's Payoff Depends on Competitive Balance, August 2003

1010 Donald O. Parsons, Torben Tranaes and Helene Bie Lilleør, Voluntary Public Unemployment Insurance, August 2003

1011 Rüdiger Pethig and Andreas Wagener, Profit Tax Competition and Formula Apportionment, August 2003

1012 Johan Willner, Privatisation and Public Ownership in Finland, August 2003

1013 Seppo Kari and Jouko Ylä-Liedenpohja, Taxation and Valuation of International Real Investments, August 2003

1014 James Heckman, Rosa Matzkin and Lars Nesheim, Simulation and Estimation of Hedonic Models, August 2003

1015 Biswa N. Bhattacharyay, Towards a Macro-Prudential Leading Indicators Framework for Monitoring Financial Vulnerability, August 2003

1016 J. Stephen Ferris and Stanley L. Winer, Searching for Keynes: With Application to Canada, 1870-2000, August 2003

1017 Massimo Bordignon, Luca Colombo and Umberto Galmarini, Fiscal Federalism and Endogenous Lobbies' Formation, August 2003 